\title{
Mesoscale modelling of smoke transport from equatorial Southeast Asian Maritime Continent to the Philippines: first comparison of ensemble analysis with in situ observations
}

\author{
Cui Ge ${ }^{1,2}$, Jun Wang ${ }^{1,2}$, Jeffrey S. Reid ${ }^{3}$, Derek Posselt ${ }^{4,5}$, Peng Xian ${ }^{3}$, Edward Hyer ${ }^{3}$ \\ ${ }^{1}$ Center for Global and Regional Environmental Research, University of Iowa, Iowa City, IA
} 52242, USA

${ }^{2}$ Department of Chemical and Biochemical Engineering, University of Iowa, Iowa City, IA 52242, USA

${ }^{3}$ Naval Research Laboratory - Monterey, Monterey, CA 93943, USA

${ }^{4}$ Department of Atmospheric, Oceanic, and Space Sciences, University of Michigan, Ann Arbor, MI 48109, USA

${ }^{5}$ Jet Propulsion Laboratory, California Institute of Technology, Pasadena, CA 91109, USA

Correspondence to: Jun Wang (jun-wang-1@uiowa.edu)

Submitted to

J. Geophys. Res. - Atmosphere

Submitted: 13 November 2016

Revised: 22 March 2017

Key Points:

- First mesoscale modelling of smoke transport from equatorial Southeast Asian Maritime Continent to the Philippines

This is the author manuscript accepted for publication and has undergone full peer review but has not been through the copyediting, typesetting, pagination and proofreading process, which may lead to differences between this version and the Version of Record. Please cite this article as doi: 10.1002/2016JD026241

This article is protected by copyright. All rights reserved. 
- Ensemble analysis of modelling uncertainties with first-ever measurement of aerosol composition data in the region of the Sulu Sea

- Meteorological initial \& boundary conditions, not cumulus parametrization \& fire emission, have the largest uncertainty in the simulation

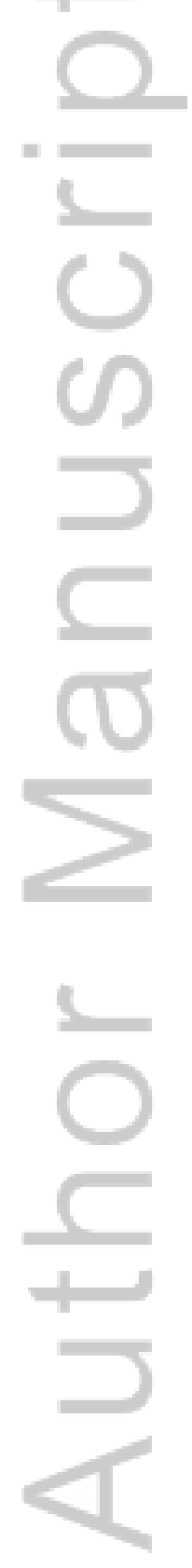

This article is protected by copyright. All rights reserved. 


\begin{abstract}
.
Atmospheric transport of smoke from equatorial Southeast Asian Maritime Continent (Indonesia, Singapore, and Malaysia) to the Philippines was recently verified by the first-ever measurement of aerosol composition in the region of the Sulu Sea from a research vessel named Vasco. However, numerical modeling of such transport can have large uncertainties due to the lack of observations for parameterization schemes and for describing fire emission and meteorology in this region. These uncertainties are analyzed here, for the first time, with an ensemble of twentyfour WRF-Chem simulations. The ensemble reproduces the time series of observed surface nonsea-salt $\mathrm{PM}_{2.5}$ concentrations observed from the Vasco vessel during 17 - 30 September 2011, and overall agrees with satellite (CALIPSO and MODIS) and AERONET data. The difference of meteorology between NCEP's FNL and ECMWF's ERA renders the biggest spread in the ensemble (up to $20 \mu \mathrm{g} \mathrm{m}^{-3}$ or $200 \%$ in surface $\mathrm{PM}_{2.5}$ ), with FNL showing systematically superior results. The second biggest uncertainty is from fire emissions; the 2-day maximum FLAMBE emission is superior than the instantaneous one. While Grell-Devenyi (G3) and Betts-MillerJanjić (BMJ) cumulus schemes only produce a difference of $3 \mu \mathrm{g} \mathrm{m}^{-3}$ of surface $\mathrm{PM}_{2.5}$ over the Sulu Sea, the ensemble mean agrees best with CMORPH's spatial distribution of precipitation. Simulation with FNL-G3, 2-day maximum FLAMBE and 800-m injection height outperforms other ensemble members. Finally, the global transport model (NAAPS) outperforms all WRF-Chem simulations in describing smoke transport on 20 Sep. 2011, suggesting the challenges to model tropical meteorology at mesoscale and finer scale.
\end{abstract}




\section{Introduction}

Biomass burning in southeast Asian Maritime Continent $\left(\mathrm{MC}, 10^{\circ} \mathrm{S}-10^{\circ} \mathrm{N}, 90^{\circ} \mathrm{E}-150^{\circ} \mathrm{E}\right.$ ), including islands of Malaysia and Indonesia, is one of the important contributors to anthropogenic aerosols and trace gases in the global tropical and sub-tropical areas (Crutzen and Andreae, 1990). The transport of smoke particles from MC to the surrounding areas is affected by multi-scale meteorological systems ranging from sea breezes, orographic flows, and tropical cyclones at regional scales to monsoons, the Intertropical Convergence Zone (ITCZ) and trade winds at continental scales (Reid et al., 2012;Xian et al., 2013;Wang et al., 2013). Furthermore, El Niño Southern Oscillation, Indian Ocean Dipole, and the Madden Julian Oscillation, can each affect the timing and strength of biomass burning as well as the atmospheric dynamical and convective processes, thereby increasing the intra-annual and inter-annual variability of the spatial and temporal distribution of smoke particles in this region (Van Der Werf et al., 2008; Reid et al., 2012). The persistent cloud cover over the MC poses a significant challenge for characterizing fire and smoke events from satellite remote sensing (Campbell et al., 2013;Hyer et al., 2013). In addition, the regional complexity in meteorology and climatology poses a challenge for modelling smoke transport and smoke interaction with radiation, clouds, and precipitation (Xian et al., 2013;Wang et al., 2013;Ge et al., 2014).

The aim of this study is to demonstrate that over the MC, an ensemble approach reveals several improvements (and corresponding insights) for understanding the ranges of uncertainties in simulating the cross-ocean regional transport of smoke particles, especially during the rainy conditions. An ensemble approach can provide an estimate of the prediction probabilities and uncertainties that derive from various sources either in the model parameterizations of key processes, or model boundary and initial conditions. As part of the 7 Southeast Asian Studies (7SEAS) field campaign (http:// 7-seas.gsfc.nasa.gov/; Reid et al., 2013;Reid et al., 2015), this

study is the third of a series of studies after Wang et al. (2013) and Ge et al. (2014). They have conducted the following process analysis with a mesoscale model Weather Research and 
Forecasting model with Chemistry (WRF-Chem), with a focus over the smoke source region (Malaysia and Indonesia) and adjacent oceans: (a) the interplay of topography, sea breeze, and tropical cyclone that regulates the smoke transport, and (b) the enhancement of smoke semidirect effect and its coupling with boundary layer processes due to persistent underlying lowlevel cloud. They further showed that the smoke injection height of $\sim 800 \mathrm{~m}$ in WRF-Chem yields good agreement of the observations from surface $\mathrm{PM}_{10}$ network and the space-born CloudAerosol Lidar with Orthogonal Polarization (CALIOP) with the modelled 3D distribution of smoke particles during the biomass burning events in Sep-Oct 2006. Building upon these progresses from our past research over the MC biomass burning source region, this study has a different focus to analyse and model the cross-ocean long-range transport of smoke particles from Malaysia and Indonesia to Philippians during convective precipitation events. This research focus is motivated by Reid et al. $(2013,2015)$ in which the transport of MC biomass burning aerosols to the Palawan Archipelago of the Philippines is documented with the first-ever measurements of aerosol composition in the region of the Sulu Sea. Consequently, the valuable measurements in Reid et al. (2013) is used in study to evaluate uncertainties in the WRF-Chem simulations of smoke transport for the MC and the Philippines region that often lacks in situ data of aerosol and meteorology, especially over the ocean.

This study is different from other past studies, such as Campbell et al. (2016) that conducted inter-comparison between WRF-Chem and ground-based lidar data, in that: (a) for the first time (to our knowledge), ship-based observations of aerosol composition data in Sulu Sea (Reid et al., 2015) are used here to evaluate a mesoscale chemistry transport model WRF-Chem; (b) the evaluation is conducted from an ensemble perspective, and ensemble members are formed through combinations of different meteorological initial and boundary conditions, smoke emission data, cumulus parameterization schemes, and smoke injection heights. We present a survey of studies that use the ensemble approach for mesoscale air quality modeling in section 2 , 
describe the data and modelling experiment in section 3, present results in section 4, and discuss and summarize the findings in section 5.

\section{Ensemble mesoscale chemistry transport modelling}

Assessing the uncertainties in model parameters and model outputs is a field of growing interest in climate and environmental prediction (Kalnay, 2002). Ensemble approaches have been used in describing the uncertainty in numerical weather prediction for many years, and followed the recognition of the chaotic nature of atmospheric dynamics and hence the importance of model initial conditions on the accuracy of numerical prediction (Kalnay, 2002). In early implementations of this approach, an ensemble of model initial conditions was used to drive the model, and the corresponding ensemble of the model outputs was analyzed to describe the probability and uncertainties for different forecast variables. Recently, the concept of ensemble prediction has been extended to include the use of different parameterization schemes and model parameter settings in generating ensemble members. However, while ensemble forecasts have been operational in all major weather prediction agencies for decades (Kalnay, 2002), only a limited number of studies have applied the ensemble concept to air quality forecasting or chemistry transport modelling as discussed below.

A meteorology-chemistry coupled model such as WRF-Chem is distinct from a weather forecast model in that it has uncertainties not only due to meteorological initial conditions and computational methods (e.g., model resolution and numerical schemes), but also from the following sources: (a) the input of emission data or the parameterizations of emission processes (normally for dust, sea salt, and biogenic sources), (b) the chemical reaction and parameterization schemes for modelling chemical species, and (c) the parameterization schemes that describe the interaction of chemical species with meteorology, such as dry/wet deposition processes, cloud chemistry, and aerosol-cloud interactions. Correspondingly, only limited work has done in the past to use ensemble analysis to study uncertainties from (a)-(c). Galmarini et al. 
(2004b) proposed the concept of ensemble dispersion forecasting; they showed the median results of radionuclide concentrations from an ensemble of 16 dispersion models were superior to the results obtained from any single ensemble member during the 1994 long-range European tracer experiment (Galmarini et al., 2004a). Mallet and Sportisse (2006) used an ensemble of 20 simulations to study the uncertainty from numerical approximations (such as grid size) and parameterization schemes for turbulence mixing, chemistry, and dry deposition in the Chemical Transport Model (CTM) for $\mathrm{O}_{3}$. They found a high uncertainty in the deterministic simulation due to parameterization schemes and suggested that the ensemble approach is necessary. Delle Monache and Stull (2003) used an ensemble of 4 different photochemical models to conduct forecasts of $\mathrm{O}_{3}$ in Europe, and they found that multi-model ensemble mean gives an overall better performance than any single ensemble member. McKeen et al. (2007) evaluated seven $\mathrm{PM}_{2.5}$ (particles of diameter less than $2.5 \mu \mathrm{m}$ ) air quality forecast models with the same set of observation data collected during the International Consortium for Atmospheric Research on Transport and Transformation/New England Air Quality Study (ICARTT/NEAQS) 2004 field study, and the ensemble-mean (calculated with equal weight for each ensemble member) was found to have the best performance. Overall, while these studies have shown improved skill in using ensemble model approaches to predict $\mathrm{O}_{3}$ (and to some extent $\mathrm{PM}_{2.5}$ ), they have focused primarily over the northern hemispheric mid-latitude regions and no emissions from biomass burning were considered. Also using the similar ensemble members as in McKeen et al. (2007), Djalalova et al. (2010) showed the combination of Kalman-Filtering and weighted averaging. $\mathrm{PM}_{2.5}$ aerosol ensembles demonstrated significant improvement gains. Rubin et al. (2016) used an ensemble of the Navy Aerosol Analysis Prediction System (ENAAPS) and did a 20 member simulation of global aerosol optical depth (AOD), and found the ensemble system is able to better capture sharp gradients in aerosol features compared against their previous system. Motivated by these past studies, our attempts here are to conduct the first ensemble analysis of a CTM over the MC region by focusing on the simulation of regional transport of smoke aerosols. 


\section{Methodology and Data}

\subsection{Observation data}

As part of the 7 Southeast Asian Studies (7SEAS) program (Reid et al., 2013), a two-week research cruise with a vessel named Vasco was conducted from 17 -30 September 2011 in the northern half of the Palawan Archipelago of the Philippines - an area thought to be a regional scale receptor for MC biomass burning and industrial emissions (Reid et al., 2012;Xian et al., 2013). This constituted the first-ever measurement of near-surface aerosol properties in the region. Instruments measuring meteorology, aerosol and gas chemistry, aerosol microphysics and optics were all employed on the cruise. Aerosol particle counters and nephelometers were located in a forward locker fed by a $4 \mathrm{~cm}$ diameter $/ 4 \mathrm{~m}$ long inlet from the top of the ship which is $35 \mathrm{~m}$. One of the primary instruments utilized in this paper was a free-standing eight-stage Davis Rotating-drum Uniform size-cut Monitor (DRUM) sampler. An unheated $\mathrm{PM}_{10}$ sample inlet was used upstream of the impactor, followed by collection stages with nominal $50 \%$ aerodynamic diameter-cut sizes of 5, 2.5, 1.15, 0.75, 0.56, 0.34, 0.26, and $0.07 \mu \mathrm{m}$. $\mathrm{PM}_{2.5}$ filters were collected by $5 \mathrm{~L} \mathrm{~min}^{-1}$ MiniVol Tactical Air Samplers (TAS). Detailed information about the measurements is referred to Reid et al.'s (2015).

Besides the Vasco cruise, two Aerosol Robotic Network (AERONET) sites (Holben et al., 1998) measure Aerosol Optical Depth (AOD) respectively at the Singapore 7SEAS super site (e.g., Atwood et al., 2013) and Kuching. To remove thin cirrus contamination and focus on fine particles from industrial and biomass burning (Chew et al., 2011;Reid et al., 2015), the daily averaged fine-mode AOD (O'Neill, 2003) generated from the Level 2.0 Spectral Deconvolution Algorithm (SDA) version is used in this study.

Moderate Resolution Imaging Spectroradiometer (MODIS) true-color images, MODIS fire products (Justice et al., 2002), and aerosol vertical profiles from CALIOP (Winker et al., 2010) are used in this study for model evaluation. MODIS detects fire pixels or infrared (IR) "hot 
spots" at $1 \mathrm{~km}$ resolution using a $4 \mu \mathrm{m}$ channel and an $11 \mu \mathrm{m}$ channel (Kaufman et al., 2003), and only MODIS level-2 fire products are used in this study. The CALIOP aboard on the CloudAerosol Lidar and Infrared Pathfinder Satellite Observation (CALIPSO) satellite launched in 2006, is a two-wavelength (532 and $1064 \mathrm{~nm}$ ), polarization-sensitive (at $532 \mathrm{~nm}$ ) lidar that measures atmospheric backscattering with a single-shot vertical and horizontal resolution of 30 $\mathrm{m}$ and $333 \mathrm{~m}$, respectively. Due to the requirements of layer classification, the current CALIOP level-2 algorithm yields an aerosol layer product at a horizontal resolution of $5 \mathrm{~km}$ and vertical resolution of $60 \mathrm{~m}$ under $20 \mathrm{~km}$. The CALIOP didn't collect any data during the cruise time period because of solar anomalies, so only 1 October 2011 (e.g., immediately after the cruise) is used to evaluate the model. The quality control flag in CALIOP level-2 product is considered to ensure the best quality layered AOD at $532 \mathrm{~nm}$. Finally, to investigate the impact of precipitation on the transport of smoke, the precipitation data provided by the Climate Prediction Center (CPC) MORPHing (CMORPH) technique (Joyce et al., 2004) is included here.

\subsection{Ensemble modeling members and experiment design}

The WRF-Chem model (Grell et al., 2005;Fast et al., 2006) is used to simulate the cross ocean regional transport of smoke from the MC. Similar to Wang et al. (2013) and Ge et al. (2014), the smoke emission inventory from FLAMBE (Fire Locating and Modelling of Burning Emissions) is used to specify the source of Black Carbon (BC) and Organic Carbon (OC) (with a OC/BC ratio of 4) as a function of time (with updates of every $\sim 6$ hours as either MODIS/Terra or MODIS/Aqua overpasses). Aerosol chemistry MADE/SORGAM (Ackermann et al., 1998; Schell et al., 2001) is used in the simulation. The size distributions of OC and BC emissions are both represented as an accumulation mode (as lognormal size distribution) with a mean volume diameter of $0.3 \mu \mathrm{m}$ and a standard deviation of 2 . The density of BC and OC is assumed to be $1.7 \mathrm{~g} \mathrm{~cm}^{-3}$ and $1 \mathrm{~g} \mathrm{~cm}^{-3}$, respectively. The hygroscopicity (size growth factor) is assumed to be 0.14 for OC and a very small nonzero value $\left(10^{-6}\right)$ for BC (Ghan et al., 2001), and hence the wet mode radius for $\mathrm{BC}$ can be diagnosed from $\mathrm{RH}$, hygroscopicity and other related 
parameters. Volume mixing rule is applied to particles. Standard processes in MADE/SORGAM such as coagulation, activation, aqueous chemistry, wet scavenging, dry deposition are all considered, although in this study, the transport and wet scavenging are the two most important. The simulation domain is showed in Figure 1c, and horizontal resolution is $27 \mathrm{~km} \times 27 \mathrm{~km}$ for each ensemble mumble. Anthropogenic emissions are included in the simulation as well, and are obtained from 2006 Intercontinental Chemical Transport Experiment (INTEX-B) estimates (Zhang et al., 2009), which include $\mathrm{SO}_{2}, \mathrm{NO}_{\mathrm{x}}, \mathrm{CO}, \mathrm{VOC}, \mathrm{PM}_{10}$ (particles of diameter less than $10 \mu \mathrm{m}$ ) and $\mathrm{PM}_{2.5}, \mathrm{BC}$, and $\mathrm{OC}$ by sector (power, industry, residential, and transportation) and six VOCs species. Corresponding emissions in nearby regions (e.g., northern Australia) are adopted from Goddard Chemistry Aerosol Radiation and Transport (GOCART) model global emissions (Olivier et al., 1996;Cooke et al., 1999;Guenther et al., 1995), which include source estimates for $\mathrm{SO}_{2}, \mathrm{BC}$, and $\mathrm{OC}$.

Two different sets of initial and boundary conditions, two cumulus parameterization schemes, two smoke emissions sources, and three smoke injection heights are used to construct the ensemble simulations. They are: (a) meteorological initial and boundary condition data from the National Centers for Environmental Prediction Final Analysis (NCEP - FNL, 1997) and European Center for Medium range Weather Forecasting (ECMWF) Re-Analysis (ERA) Interim; (b) the Grell-Devenyi (G3) and Betts-Miller-Janjic (BMJ) cumulus schemes; (c) two versions of FLAMBE emissions including the old version of emission product (e1) and the new version 2day maximum flux emissions (e2), respectively; and (d) three smoke emission injection heights $500 \mathrm{~m}, 800 \mathrm{~m}$, and $1200 \mathrm{~m}$ respectively. Together, the combinations of these simulation options form twenty-four ensemble members. We briefly introduce each of the ensemble members sequentially in the section below.

\section{a. Model initial and boundary conditions for meteorology}


The NCEP-FNL data is widely used to drive WRF-Chem, and was shown in our previous studies to provide reasonable initial and boundary conditions for the simulations over the MC smoke source region (Wang et al., 2013;Ge et al., 2014). ERA-Interim is the latest global re-analysis produced in Europe with a four-dimensional variational (4DVAR) data assimilation system (Dee and Uppala, 2009;Dee et al., 2011). NCEP-FNL is an analysis while ERA-Interim is a reanalysis of meteorological data. The major differences between analyses and re-analysis data are that re-analysis data may include larger amounts of assimilated observational data, and reanalysis systems utilize a consistent forecast and data assimilation system over the entire reanalysis time frame. The advantage of the re-analysis is that the same model physics, parameterizations, etc., are used for the entire dataset produced. By contrast, operational analyses (e.g., the NCEP-FNL data) have some inconsistencies over time (Carvalho et al., 2014). ERAInterim is output on a $0.75^{\circ} \times 0.75^{\circ}$ horizontal resolution grid, and it has 60 hybrid vertical levels from $1010 \mathrm{hPa}$ to $0.1 \mathrm{hPa}$, in which $\sim 10$ vertical levels are from surface to $900 \mathrm{hPa}$. The NCEPFNL data is output on a $1^{\circ} \times 1^{\circ}$ horizontal grid with 26 vertical layers including 5 levels from surface to $900 \mathrm{hPa}$.

While this study and our previous studies (Wang et al., 2013;Ge et al., 2014) have used the NCEP-FNL analysis data in simulating the smoke transport over fire source regions in the MC, some studies (Carvalho et al., 2014) reported that ERA-Interim data overall has more fidelity than other analysis/re-analysis data. Here, we run the simulation with NCEP-FNL and ERAInterim, respectively to evaluate the impact of their differences in modelling regional transport of smoke aerosols.

\section{b. Cumulus schemes}

Two cumulus schemes, G3 (Grell and Dévényi, 2002) and BMJ (Janjic, 1994), are used in this study, as they both are coupled with wet deposition process for aerosols in WRF-Chem. Several other options of cumulus schemes such as Kain-Fritsch scheme, Tiedtke scheme and Zhang- 
McFarlane scheme, while can be used for precipitation simulation, are not coupled with the wet deposition processes and therefore, are not used in this study. Based on the study of Nasrollahi et. al. (2012), we use the microphysics scheme of Lin et al. (1983) in all the simulations. Nasrollahi et. al. (2012) used a total of 20 combinations of microphysics and cumulus schemes in their study, and they reported that the tropical cyclone track was best estimated using the Lin et al (1983). Both aerosol-cloud interactions and aerosol direct radiative feedbacks are intertwined with other meteorological and chemical process in regulating the smoke aerosol transport. In order to untangle these relationships and focus on the impacts of model initial and boundary conditions, wet deposition processes, and emissions on aerosol transport, no aerosol-cloud interaction nor aerosol direct radiative feedbacks are considered the model simulation.

\section{c. Emissions}

Two sets of fire emission inventory are used in the simulation: one is the old version FLAMBE fire emissions (e1)(Reid et al., 2009; Hyer et al., 2013), and the other is the two-day maximum (previous day and present day, new version) FLAMBE flux emissions (e2). FLAMBE is based on the satellite active fire hotspots detections. e1 takes account of fire signals detected by both polar orbiting (MODIS to be specific) and geostationary satellites (GOES, the Geostationary Operational Environmental Satellite system), while e2 uses those detected by MODIS only and applies regionally tuned multipliers on the two-day maximum fire signals. The two-day maximum fire emission inventory is used to minimize the missing fire spots because of the orbital coverage or cloud cover. It assumes a self-sustained nature to the fires and it is comparable with other current fire emissions product (e.g., Wiedinmyer et al. 2011). It was also shown to improve biomass burning smoke modeling skill in the NAAPS AOD re-analysis(Lynch et al., 2016).

\section{d. Smoke injection heights}

The wind patterns in both speed and direction below and above planetary boundary layer (PBL) is often in opposite direction over MC (Wang et al., 2013;Reid et al., 2015). Wang et al. (2013) 
shows that different vertical profile of $\mathrm{PM}_{2.5}$ over MC can be simulated in WRF-Chem simply because of different injection heights. However, the focus of that study is smoke transport from Sumatra and Borneo to surrounding area such as Singapore and Malaysia, while the current study is focusing on cross-ocean regional transport of smoke from Sumatra and Borneo to Philippian. To investigate the uncertainties induced by smoke injection height in this context, the injection height of smoke particle (OC and BC) emissions is specified as $300 \mathrm{~m}, 800 \mathrm{~m}$ and 1200 $\mathrm{m}$ above the surface. Within the injection height, the emissions are uniformly distributed (Wang et al., 2013; Ge et al., 2014). It is noted that boundary layer height in our study region is normally low ( 500-700 $\mathrm{m}$ in daytime, Wang et al., 2013), and therefore, smoke injection height is critical for simulating the long-range transport of smoke above the boundary layer.

\subsection{NAAPS Data}

The Navy Aerosol Analysis and Prediction System (NAAPS) is the U.S. Navy's global aerosol analysis and forecast model (http://www.nrlmry.navy.mil/aerosol/). It makes 6-day forecasts, 4 times a day at 1/3 degree spatial resolution and 42 vertical levels driven by the Navy Global Environmental Model (NAVGEM, Hogan et al., 2014, formerly the Navy Global Atmospheric Prediction System NOGAPS) meteorology. NAAPS has supported various operations and research, including the monitoring of biomass burning plumes for the maritime continent region (e.g., Hyer and Chew, 2010; Reid et al., 2012; Xian et al, 2013). The recently developed decadelong 1x1 degree and 6-hourly aerosol optical depth (AOD) re-analysis product (Lynch et al., 2016) utilizes a modified NAAPS as its core and assimilates quality controlled retrievals of AOD from Moderate Resolution Imaging Spectroradiometer (MODIS) on Terra and Aqua and the Multi-Angle Imaging Spectroradiometer (MISR) on Terra (Zhang et al., 2006; Hyer et al., 2011; Shi et al., 2014). It uses the FLAMBE e 2 smoke emission, and aerosol wet deposition is driven by CMORPH precipitation within the Tropics. The NAAPS surface concentration data used in this paper are extracted from the same NAAPS re-analysis run. A parallel NAAPS run without 
AOD data assimilation yields similar result for the study period and location. The NAAPS simulated results are only shown in Figure 1(a) and the detailed information is referred to Reid et al. (2015)'s study.

\section{Results}

All twenty-four ensemble member simulations are initiated at 00:00 UTC on 1 September 2011 and ended at 00:00 UTC on 30 September 2011. The model boundary conditions for meteorology are specified four times a day, at 00:00, 06:00, 12:00 and 18:00 UTC, respectively. Analysis is conducted only for 17-30 September 2011 during which the Vasco cruise observation was undertaken (Reid et al., 2015). To focus on the analysis of fine mode particles from industrial and biomass burning emissions, simulated sea salt concertation is excluded from $\mathrm{PM}_{2.5}$ mass presented in this manuscript.

\subsection{Overall evaluation of ensemble simulation}

Figure 1a shows the comparison of simulated ensemble-mean of surface $\mathrm{PM}_{2.5}$ (red line) with Vasco Cruise observed $\mathrm{PM}_{2.5}$ (black dots). The trajectory of Vasco Cruise is shown as white line in Figure 1c. During 17 - 30 September 2011, Vasco cruise observed 3 stages of the smoke transport characterized with lower $\mathrm{PM}_{2.5}$ concentrations before Sep. 23, higher $\mathrm{PM}_{2.5}$ mass afterwards until Sep. 27, then a steep rise of $\mathrm{PM}_{2.5}$ mass after Sep. 29 (Fig. 1a). Overall, the ensemble-mean of $\mathrm{PM}_{2.5}$ concentration agrees well with the time series of the measured counterparts within these 3 time periods except an underestimate of $\mathrm{PM}_{2.5}$ during the last 2 days (Sep. 29 and 30) of the field campaign. The linear correlation between hourly ensemble mean and observed $\mathrm{PM}_{2.5}$ is statistically significant $(\mathrm{p}<0.05)$ with coefficient $\mathrm{R}$ of 0.88 . It should be noted that during 26 - 29 September 2011, Vasco cruise stayed in a harbour due to the tropical cyclone impact.

For comparison, the NAPPS results are shown in Figure 1(a). NAAPS simulation outperforms 
WRF-Chem ensemble simulation with larger correlation of 0.97 and less RMSE of 3.00. The aerosol wet deposition in NAAPS simulation is driven by CMORPH precipitation within the tropics (Xian et al, 2013), and that may contribute to their better agreement with the observations. However, since the smoke transport episode during Sep 27 to Sep 29 was missed by Vasco, it is difficult to evaluate the performance of FNL and ERA in the period. Hence, we further discuss the impact from precipitation on aerosol transport after Sep. 29 at Section 4.3. In this study, NAAPS simulated results are only showed in Figure 1(a) and the detailed information is referred to Reid et al. (2013)'s study. Although WRF-Chem shows about $10 \mu \mathrm{g} \mathrm{m}^{-3}$ low bias after Sep 29, WRF-Chem simulated $\mathrm{PM}_{2.5}$ amount gives a better agreement with the observation than NAAPS during Sep. 17 - 27. NAAPS captures the high $\mathrm{PM}_{2.5}$ value after Sep 29. The composite analysis for the low bias of Sep. 29th-30th simulation is further discussed in Section 4.4 and Section 4.6 from the emission and meteorological perspective, respectively.

The simulated AOD fields are also evaluated for two AERONET sites that have data for our study time period. Figure 1d for Kuching at Borneo Island and Figure 1e for Singapore both show that the time series of ensemble mean of AOD captures well the high AOD values during Sep. 23 - Sep. 26. At Kuching the simulations slightly underestimate the AOD on Sep 22, but show a larger underestimation during Sep 28 - 30 (not show). We also noticed that the big discrepancy on Sep 25 at Kuching; the overestimation from simulation might be caused by the unreal big fire emissions at Kuching or close fire source area. The correlation between Kuching observed AOD and simulated AOD is 0.55 , and the correlation for Singapore is negative and not significant. It is suspected that the fire emissions might have missed detections on some fires for the last three days (September 28, 29 and 30); the detail will be discussed in Section 4.4. Daily averaged instead of hourly AOD comparison between the observation and simulation (Fig. S2) also shows same main features. After removing the data in these three days, the simulation and observation turned to be highly correlated with correlation coefficient as 0.94 for Kuching and 0.68 for Singapore. 
While the ensemble mean overall is in good agreement with the observed $\mathrm{PM}_{2.5}$ and AOD, we also found large spreads among ensemble members with the variations up to $20 \mu \mathrm{g} \mathrm{m}^{-3}$ for $\mathrm{PM}_{2.5}$ and 0.6 for AOD (shown as the error bar in Figure 1). To investigate the causes of the discrepancies among each ensemble member and the low bias of simulation for Sep. 29 and 30, we conduct the following analysis specifically for model configurations, fire emission and meteorology initial condition.

\subsection{Uncertainty from meteorological initial and boundary conditions}

We divided all ensemble members into two sub-groups; one sub-group consists of simulations driven with FNL initial and boundary conditions (Figure 2a), while the other is driven with ERA (Figure 2b). FNL-driven simulations show a smoke transport event from Sep 27 to Sep 28. In contrast, the ERA-driven simulations show the transport beginning and ending in just one day (Sep 28). Both FNL-driven and ERA-driven simulations show an increase of $\mathrm{PM}_{2.5}$ after Sep 29. FNL-driven simulations capture the timing and the magnitude of the $\mathrm{PM}_{2.5}$ fluctuations reasonably well, with a correlation coefficient of 0.91 and RMSE (Root Mean Square Error) of $5.62 \mu \mathrm{g} \mathrm{m}^{-3}$ compared with Vasco observations. The ERA-driven simulations show a delay in the $\mathrm{PM}_{2.5}$ increase and an overall smaller amount during the Sep. 29 event. In addition, the correlation coefficient is smaller (0.78), and RMSE is larger $\left(6.94 \mu \mathrm{g} \mathrm{m}^{-3}\right)$ than the corresponding FNL-driven simulations. The differences in $\mathrm{PM}_{2.5}$ mass that arise from the use of either FNL or ERA meteorology can be up to $20 \mu \mathrm{g} \mathrm{m}^{-3}$ for hourly data and for some extreme fire transport events such as on Sep. 28 (Figs. 2a and 2b).

A summary evaluation of the FNL- and ERA-driven simulations is provided in Figure 2c in the form of a Taylor diagram (Taylor, 2001). This chart provides a statistical summary of the model performance in terms of correlation coefficients ( $\mathrm{R}$, cosine of polar angles), normalized rootmean-square difference (RMSD, radius from the observation dot), and ratio of standard 
deviations between model and observations (normalized standard deviation - NSD, $x$ and y axis). The observation is placed at the point at which R and NSD are unity. FNL-driven ensemble members have correlations with observations of between 0.75 to 0.98 , while ERA-driven simulations have correlations with observation of between 0.6 and 0.8 . The labelled numbers in Figure $2 c$ are pairs of simulation configurations that are identical except for their driving meteorological analysis (FNL-driven or ERA-driven). The difference in correlation can be up to 0.35 between pairs (e.g., pair 2), and the difference in normalized standard deviation can be as large as 0.4 (again, pair 2). Generally, all the simulations have a relatively low bias of $\sim 30 \%$.

To understand the difference between FNL-driven simulations and ERA-driven simulations, we examine simulations FNL-G3-e2-800 and ERA-G3-e2-800 as specific examples. Figure 3 shows the spatial distribution of hourly $\mathrm{PM}_{2.5}$ distributions at every 12-hour interval during 12:00 UTC Sep. 27-00:00 UTC Sep. 29 of 2011. Generally, the cruise area was influenced by smoke plumes transported from both Sumatra (west plumes) and Borneo (east plumes). At 12:00 UTC on Sep. 27, the FNL-driven simulation shows a directly smoke transport from both Borneo island and Sumatra to the cruise area (circle). In contrast, in the ERA-driven simulation, the eastern plume stretched to the northeast, merging with the tropical cyclone and bypassing the cruise area by a narrow margin. The western plume of smoke in both simulations is aimed directly toward the cruise area. On 00:00 UTC Sep. 28, the western smoke plume in the FNL simulation had already reached the Vasco area, and combined with the eastern smoke plume leading to a dramatic increase in $\mathrm{PM}_{2.5}$. In the ERA-driven simulation, the western smoke plume went to the south of the Vasco area and then move northward along with the tropical cyclone, and didn't hit the Vasco area. At this point, rainfall has some effect on the smoke transport, which will be analyzed in detail in the following section in the context of the cumulus scheme and associated precipitation-induced uncertainties. On 12:00 UTC Sep. 28, in the FNL simulations, under the influence of the tropical cyclone, the western plumes and eastern plumes went northeast as two branches, between which with the cruise was conducted, thereby rendering lower $\mathrm{PM}_{2.5}$ 
compared with what was observed 12 hours previously. In the ERA simulation, the western smoke plume passed through the cruise area and kept the simulated $\mathrm{PM}_{2.5}$ at a very high value. On 00:00 UTC of Sep. 29, in the FNL simulation, the eastern smoke plume reached the cruise area and reproduced the observed peak value (Figure 2a). In the ERA simulation, the western plume surrounded the cruise area from the west, and the eastern plume was advected to the east following another tropical cyclone.

\subsection{Uncertainty from cumulus parameterization and precipitation}

Over the equatorial ocean, heavy precipitation often accompanies a strong tropical cyclone, and wet deposition could be a key mechanism influencing smoke transport. This study does not include aerosol direct nor in-direct radiative feedbacks, and here we focus on the potential rain washout impact on the MC smoke transport process. In the simulations, the convective activity, the precipitation pattern and amount are directly affected by the cumulus scheme. Figure 4a shows the ensemble of simulations run with the G3 cumulus scheme, and Figure $4 \mathrm{~b}$ shows the ensemble simulations run with the BMJ cumulus scheme. For most days, these two ensemble simulations have similar behaviour for the $\mathrm{PM}_{2.5}$ variations, with comparable correlation coefficient and RMSE: 0.90 and 6.33 respectively for G3 verses 0.87 and 6.16 for BMJ simulation. The primary differences are found during 18:00 UTC of Sep. 27 - 06:00 UTC of Sep. 28. The G3 ensemble shows two peak values respectively around 18:00 UTC of Sep. 27 and 06:00 UTC of Sep. 28 with values of $\sim 20 \mu \mathrm{g} \mathrm{m}^{-3}$. In contrast, the BMJ ensemble shows gradual increase of $\mathrm{PM}_{2.5}$ from 12:00 UTC of Sep. 27 to 06:00 UTC of Sep 28 with a peak value of 23 $\mu \mathrm{g} \mathrm{m}^{-3}$. The overall uncertainties associated with the use of G3 or BMJ cumulus scheme are only within $3 \mu \mathrm{g} \mathrm{m} \mathrm{m}^{-3}$ during the Vasco observed time period. A detailed discussion of precipitation and the interactions between rain and smoke transport affected by different cumulus scheme follows. 
Figure 5 shows hourly mean precipitation during 17 - 30 September 2011 from CMORPH observations, and from simulations using different meteorology and cumulus schemes (FNL-G3, FNL-BMJ, ERA-G3, ERA-BMJ) as well as the ensemble mean of the above 4 simulations. Compared with the CMORPH observed precipitation, G3 cumulative scheme shows significant low bias mostly between $0.1-1 \mathrm{~mm} \mathrm{hr}^{-1}$ in both the tropical cyclone area and the surrounding ocean area during the 2-week period, regardless of which meteorological data is chosen to drive WRF-Chem. On the contrary, BMJ cumulative scheme yields similar magnitude of precipitation for both the tropical cyclone area $\left(\sim 1.3 \mathrm{~mm} \mathrm{hr}^{-1}\right)$ and ocean area $\left(\sim 0.3 \mathrm{~mm} \mathrm{hr}^{-1}\right)$. Figure 6 further provides a statistical evaluation in the form of a Taylor diagram, and the relative biases are presented by different colours. The Taylor diagram shows the ensemble mean outperforms other simulations with greater spatial correlation of $\sim 0.6$ and lower bias of less than $5 \%$. Comparing with CMORPH observation and FNL driven simulation, ERA reanalysis data brings high amount of precipitation larger than $1.7 \mathrm{~mm} /$ hour along the longitude of $98^{\circ}$ at both around $18^{\circ}$ latitude and north of Sumatra, especially in the BMJ-ERA results (Figure 5f). This high bias of precipitation results in larger standard deviation in the BMJ-ERA ensemble (point 4 in Figure 6).

From hourly time series of precipitation from both simulation and Vasco observation (Fig. S3), we found the simulations missed heavy precipitations for several hours such as 3 hours on Sep. 24, an hour on Sep. 27, 3 hours around Sep. 29. For modeled $\mathrm{PM}_{2.5}$ along Vasco path, it depends on both the precipitation at Vasco place and the precipitation along the smoke transport pathway from fire source area to Vasco place, especially the latter. To understand the possible interface between precipitation and smoke plumes, Figure 7 shows 6-hour total rain amount during Sep. 27 of 2011. On 6:00 UTC of Sep 27, the G3 simulation only produces precipitation around the tropical cyclone center and misses the precipitation over the ocean area where CMORPH shows more than $20 \mathrm{~mm}$ precipitation. On Figure 7, the smoke transport pathways are outlined with white contours which are for $\mathrm{PM}_{2.5}$ of $20 \mu \mathrm{g} \mathrm{m}^{-3}$. The BMJ simulation (Figure $7 \mathrm{~g}$ ) shows more than $10 \mathrm{~mm}$ rainfall on the west plume pathway to Vasco place (denoted as pink square on each 
panel of Figure 7), although it still underestimates the precipitation compared with CMORPH and hence underestimate the wet deposition of $\mathrm{PM}_{2.5}$. At 12:00 UTC of Sep. 27, the eastern plume in both G3 and BMJ simulations (Figure 7e and h) reached the location of the Vasco. In BMJ simulation, the rain over Vasco area is more than $20 \mathrm{~mm}$ and the G3 simulated rain is less than $10 \mathrm{~mm}$. On 18:00 UTC of Sep 27, the west plume and east plume combined together and passed through Vasco area, leading to high concentration of $\mathrm{PM}_{2.5}$ at that time. After Sep. 28, both CMORPH and simulations consistently show no precipitation in the study area.

\subsection{Uncertainty from smoke emissions}

Figure 8a shows the ensemble of simulations with el emission, which is the older version of FLAMBE fire emission, Figure $8 \mathrm{~b}$ shows the ensemble simulations with e 2 emissions which is two-day maximum (previous day and present day) newer version FLAMBE flux emissions. As expected, E2 emission renders higher value of simulated $\mathrm{PM}_{2.5}$ around Sep 25, 26 and 29. It also provides better agreement with Vasco observation than el emission with higher correlation coefficient (0.90 vs. 0.85) and less RMSE (5.42 vs. 7.09).

FLAMBE fire emission products are compiled based on MODIS fire data. For southeast Asia, huge challenges exist in satellite monitoring of fires. Orbital gaps at satellite swath edges near the equator often decrease the number of available MODIS overpasses (Hyer et al., 2013). The diurnal cycle of fire could be missed due to lack of coverage from polar-orbiting satellites in the Maritime Continent. In addition, it is difficult to detect many low thermal signatures from smoldering peat fires (Reid et al., 2013). On the top of these complications, the cloud coverage is frequently high over MC and hence resulting in missing fire detections.

To investigate the low bias of simulated $\mathrm{PM}_{2.5}$ during Sep 27 - 29 in all the ensemble members, we examined both Terra and Aqua true color images. These 3 days experienced a strong tropical cyclone from generation (Sep 27) to intensification (Sep 28) and landfall on Sep 29. On Sep 27 
and 28, fire detection was impossible due to overlying cloud cover especially for Sep 27 . On Sep 28, both Singapore and Kuching are close to the edge of the satellite swath, and therefore, fire spots (especially those small fires) at these two areas are missed in satellite detection. FLAMBE emission inventory with 2-day maximum flux (e2) shows quite low fire flux during Sep 27 and Sep 28 potentially leading to a low bias in simulated surface $\mathrm{PM}_{2.5}$ on the flowing days (Sep 28 and 29). MODIS AOD data shows very little area with valid retrievals during Sep 27 and 28, which also indicates unfavorable weather conditions for satellite data to detect fires.

Here we only take September 29 as an example to show uncertainties caused by fire emission. Aqua true color image (Figure 9b) shows a large amount of fire spots over southwest of Borneo Island around Kuching, while the FLAMBE (Figure 9c) from its routine processing doesn't have any fire spots around Kuching. We constructed an updated emission data for Sep 29 in the following method. First, the location data (longitude and latitude) of fire pixels from both Terra and Aqua were obtained on Sep. 29. Second, to avoid missing possible fire spots, the fire spots in FLAMBE e2 for Sep. 29 are included in the updated fire spots data set. Third, averaged fire emission flux per fire pixel (based on FLAMBE e2) in the two weeks of this study time period is calculated over the fire area. Finally, this mean fire flux is applied to all the fire spots (as updated in the first and second step).

The simulated AOD using the FLAMBE e2 (with our updates) show the AOD around Kuching is less than 0.2, and the simulation using the updated FLAMBE fire emission shows similar amount of AOD as the AERONET observed value of $\sim 0.4$ at Kuching. The updated emission is aimed to provide a comparative dataset, rather than replacing e 2 emissions, and the update approach is not intended to be a systematically optimal solution. Indeed, with this updated emission, the WRFChem simulation still misses the observed peak of $\mathrm{PM}_{2.5}$ on Sep. 29 (figure not shown). Nevertheless, such integrated study of simulation, surface-based observations, satellite true color images, satellite fire hot spots and satellite AOD products provided a powerful means to reveal 
the uncertainty of the fire emissions. Because of inherent limitations in satellite-based fire detection method for cloudy conditions and the gaps between MODIS' ground-tracks in the equator, there is no one-size-fits-all solution that would improve the fire emission estimate everywhere and at any time. Here we only focus on the case study and discuss the possible emission impact in our ensemble simulation.

\subsection{Uncertainty from injection heights}

Figure 10 shows the simulations with three injection heights, which are $300 \mathrm{~m}, 800 \mathrm{~m}$ and 1200 m. As expected, the simulation with lower smoke injection heights has higher surface $\mathrm{PM}_{2.5}$ (Figure 10a, b, c). The uncertainty due to the variation of injection heights could be up to $4.5 \mu \mathrm{g}$ $\mathrm{m}^{-3}$ (35\% compared to the lowest PM2.5 value simulated with $1200 \mathrm{~m}$ injection height) for the peak value around 00:00 UTC on Sep. 28, and for all the other times the uncertainty is within 2 $\mu \mathrm{g} \mathrm{m}^{-3}$. The simulation with smoke injection height of $800 \mathrm{~m}$ has the best performance with higher correlation and lower RMSE, and the simulation with $300 \mathrm{~m}$ injection height has the worst performance (Figure 10).

Smoke vertical distribution is compared with CALIOP-derived vertical profile of aerosol extinction coefficient in Fig. 11. Due to solar flare activity, CALIPSO data is not available for 22 to 30 September of 2011 and the data for 1 October is used to verify the simulation results. Figure 11a is for 05:34 UTC which is MC local afternoon (the most active fire burning time). Figure 11a shows that over Borneo fire source area, the smoke aerosol could be at up to $4 \mathrm{~km}$ and over the South China Sea the aerosol layer is confined within $2 \mathrm{~km}$. It should be noted that some spikes of aerosol extinction coefficient from continuous background above $2 \mathrm{~km}$ is most likely cirrus contamination. The simulations with smoke injection height of $300 \mathrm{~m}$ (Figure 11b) and $800 \mathrm{~m}$ (Figure 11c) show that most aerosol particles are within $2 \mathrm{~km}$ from the surface; these simulations agree with the CALIPSO data. However, the simulation with smoke injection height of $1200 \mathrm{~m}$ (Figure 11d) shows too much smoke between $2 \mathrm{~km}$ and $4 \mathrm{~km}$ which is not observed at 
CALIPSO data. Reid et al. (2013) addressed the same vertical structure and found most aerosol particles mixed through a deep planetary boundary layer (below $3 \mathrm{~km}$ ) and stayed in that lowest portion of the atmosphere.

\subsection{Composite analysis for Sep. 29th-30th}

Since the fire emission is not a factor for low bias in the modeled $\mathrm{PM}_{2.5}$ compared to the VASCO measurements during Sep 29-30 (as discussed in Section 4.4), we in this section focus on the impact of the meteorology on WRF-Chem results in these 2 days. It is suspected WRF-Chem finer resolution simulation is vulnerable for the possible meteorology errors. For example, the difference of wind directions may cause the certain model grid box missing the smoke event. We did an up-scale test by using the maximum $\mathrm{PM}_{2.5}$ value over the $50 \mathrm{~km}$ radius of circle surrounding the certain model grid box for the data after September 29. Figure 1(b) shows the maximum ensemble mean (Ensemble 2) achieves larger correlation coefficient (from 0.88 to 0.96). Figure $\mathrm{S} 1$ in supplementary shows another up-scale $\left(1^{\circ} \times 1^{\circ}\right.$ degree $)$ ensemble $\mathrm{PM}_{2.5}$ which also has better performance than the base ensemble simulation. We also did a nested grid simulation with $27 \times 27 \mathrm{~km}^{2}-9 \times 9 \mathrm{~km}^{2}$ horizontal resolution simulation for the same time period (not shown), and didn't find any improvement for Sep 29 and Sep 30. In contrast, NAAPS model at resolution of 1 degree with the exact same fire emission as used in half of our ensemble members was able to yield better agreement with the observed significant increase of $\mathrm{PM}_{2.5}$. This counterintuitive result suggests that models with finer-resolution may not be able to capture the exact timing and location of smoke transport pathways at the individual grid spacing.

To further analyze the smoke transport pathway in these two days, we take Sep 30 18:00 as an example (Figure 13) to look at the differences between an FNL driven simulation and an ERA driven simulation. The simulated $\mathrm{PM}_{2.5}$ from FNL driven simulation is about $11 \mu \mathrm{g} \mathrm{m}^{-3}$, while the value is about $20 \mu \mathrm{g} \mathrm{m}^{-3}$ in the ERA driven simulation. Figure $13 \mathrm{~b}$ shows there is a convergence area when the west branch smoke plume reached the tropical cyclone (northwest of 
Vasco), after which the high amount of $\mathrm{PM}_{2.5}$ is subsequently pushed by the cyclone to Vasco place. FNL-driven simulation (Figure 13a) shows that the west branch of smoke plume is mostly transport to the far northwest of Vasco over the southwest of the cyclone. Figure 13c shows the difference of wind between ERA driven simulation and FNL driven simulation. Because these 2 simulations gave different locations of the tropical cyclone, we can see more than $20 \mathrm{~m} \mathrm{~s}^{-1}$ difference of the wind speed around the tropical cyclone area. In average, 2-3 $\mathrm{m} \mathrm{s}^{-1}$ wind speed difference could be seen in the domain. Besides the cyclone area, the west branch of smoke path way shows up to $4 \mathrm{~m} \mathrm{~s}^{-1}$ wind speed difference. The ERA wind direction is more eastward, and the FNL wind direction is more northward. This case illustrates that the dependence of mesoscale model on meteorology data can cause about $9 \mu \mathrm{g} \mathrm{m}^{-3}$ PM2.5 discrepancies when comparing against point observation. Satellite images on 2011 Sep. 30 17:32, 18:32 and 19:32 UTC are shown in Figure 13. The cyclone location and progress from FNL simulation is more close to the image on 17:32 UTC and the ERA simulation is more close to the image on 18:32 UTC. This indicates one-hour delay of certain meteorology condition can introduce big wind speed and PM2.5 discrepancy as discussed in this case. Hence, the ensemble simulation approach using different meteorology data enables reduction of uncertainties beyond the simulation from individual meteorology condition.

\section{Discussion and conclusions}

This study conducted the first ensemble analysis of a mesoscale CTM over the MC, focusing on the cross-ocean regional-scale transport of smoke aerosol. The ensemble members are formed through combinations of different meteorological data, smoke emission data, cumulus parameterization scheme, and smoke injection height. The Vasco cruise observation of aerosol composition data in Sulu Sea set up a best receptor area for investigating the smoke transport

from both Sumatra (west plume) and Borneo (east plume). The evaluation is conducted from an ensemble perspective, and the simulation of ensemble mean generally reproduces the regional scale smoke transport for different stages, though missing the high values on Sep. 30 of 2011. 
Piece-wise analysis of each set of ensemble members show that the biggest simulation uncertainty (up to $200 \%$ for surface aerosol mass) is introduced by meteorology initial condition and boundary condition, and FNL-driven simulations generally outperformed ERA-driven simulations for the time period of study. FNL-driven members are in better agreement with observed PM2.5 with a linear correlation coefficient R values of 0.8 - 0.95 (in contrast to 0.6 0.8 of ERA-driven). The second major source of uncertainty is due to different fire emission data; the 2 day maximum FLAMBE emission gives superior results (especially during the heavy smoke event on 29 Sep. 2011), as compared with the old version of FLAMBE emission. While comparing with Vasco observed time series, the cumulus scheme and the wet deposition does not play the leading role in the simulations, and the $\mathrm{PM}_{2.5}$ uncertainties brought by $\mathrm{G} 3$ and BMJ cumulus scheme is within $3 \mu \mathrm{g} \mathrm{m}^{-3}$ because no or very little precipitation around $\mathrm{PM}_{2.5}$ peak value time period which is Sep 29 and 30 of 2011. However, for the two weeks' average over the study domain, the ensemble mean gives best description of spatial distribution of precipitation, with correlation of $\sim 0.6$ and mean bias of less than $5 \%$ as compared against the observationbased CMORPH data. From the two weeks' average, the cumulus scheme G3 underestimates the precipitation over most MC ocean area up to $0.8 \mathrm{~mm} \mathrm{hr}^{-1}$ during the active tropical cyclones time period. The BMJ cumulus scheme has slightly underestimate of precipitation in Borneo coast area convection. The ensemble mean of precipitation gives a best agreement with the observation. For smoke injection height, the simulation with $800 \mathrm{~m}$ set up is the best and the simulation with $300 \mathrm{~m}$ set up is the worst. Among the 24 ensemble members, the simulation of FNL-G3-e2-800 has the best performance.

The integrated analysis of simulation, ground based observation and satellite data reveals missing fire emissions could cause Aerosol Optical Depth (AOD) underestimation of $~ 0.2$ at Kuching of a fire source area. However, the uncertainties in meteorology appear to have an equally large (if not lager) impact for simulation of long-range transport of smoke particles in the MC region. It is shown that WRF-Chem simulation with finer solution may not necessarily yield 
more accurate description of meteorology in space and time; in some cases, simulations with coarser resolution driven by reliable meteorological fields may provide the first-order characterization of spatial and temporal variation of aerosol field that are affected by the longrange transport of aerosols. The available observation data for the evaluation in this study is limited for short period, long term observation and analysis are needed. With the Global Precipitation Mission (Hou et al, 2014) and more and more surface observation from various mobile platforms, future studies may use these new observations to improve the estimate/simulation of meteorological fields, especially the fields of precipitation. Further investigations will include aerosol direct, semi-direct effects (Grell and Baklanov, 2011; Yang et al., 2011; Ge et al., 2014) and indirect effect (Forkel et al., 2015; Rosenfeld and Woodley, 2000) in our ensemble analysis.

\section{Acknowledgements}

The NASA Interdisciplinary Science Program supports this study. Dr. Jeffrey S. Reid's contribution was also partially supported by the NRL 6.1 base program. The authors thank the Holland Computing Center of University of Nebraska - Lincoln, its director Dr. David Swanson and his staff Dr. Jingchao Zhang and Dr. Adam Caprez for their helpful efforts with computing work. All the data presented in this manuscript can be obtained through email to J. Wang (junwang-1@uiowa.edu)

\section{References}

Ackermann, I. J., Hass, H., Memmesheimer, M., Ebel, A., Binkowski, F. S., and Shankar, U.: Modal aerosol dynamics model for Europe: Development and first applications, Atmos. Environ., 32, 2981-2999, doi:10.1016/S1352-2310, 1998.

Armstrong, E. M., Wagner, G., Vazquez-Cuervo, J., and Chin, T. M.: Comparisons of regional satellite sea surface temperature gradients derived from MODIS and AVHRR sensors, International journal of remote sensing, 33, 6639-6651, 2012. 
Atwood, S. A., Reid, J. S., Kreidenweis, S. M., Liya, E. Y., Salinas, S. V., Chew, B. N., and Balasubramanian, R.: Analysis of source regions for smoke events in Singapore for the 2009 El Nino burning season, Atmospheric Environment, 78, 219-230, 2013.

Campbell, J. R., Reid, J. S., Westphal, D. L., Zhang, J., Tackett, J. L., Chew, B. N., Welton, E. J., Shimizu, A., Sugimoto, N., and Aoki, K.: Characterizing the vertical profile of aerosol particle extinction and linear depolarization over Southeast Asia and the Maritime Continent: The 2007-2009 view from CALIOP, Atmospheric Research, 122, 520-543, 2013.

Campbell, J. R., Ge, C., Wang, J., Welton, E. J., Bucholtz, A., Hyer, E. J., Reid, E. A., Chew, B.

= N., Liew, S.-C., Salinas, S. V., Lolli, S., Kaku, K. C., Lynch, P., Mahmud, M., Mohamad, M., and Holben, B. N.: Applying Advanced Ground-Based Remote Sensing in the Southeast Asian Maritime Continent to Characterize Regional Proficiencies in Smoke Transport Modeling, Journal of Applied Meteorology and Climatology, 55, 3-22, 10.1175/jamc-d-15-0083.1, 2016.

Carvalho, D., Rocha, A., Gómez-Gesteira, M., and Santos, C. S.: WRF wind simulation and wind energy production estimates forced by different reanalyses: comparison with observed data for Portugal, Applied Energy, 117, 116-126, 2014.

Chew, B. N., Campbell, J. R., Reid, J. S., Giles, D. M., Welton, E. J., Salinas, S. V., and Liew, S. C.: Tropical cirrus cloud contamination in sun photometer data, Atmospheric environment, 45, 6724-6731, 2011.

Cooke, W., Liousse, C., Cachier, H., and Feichter, J.: Construction of a $1 \times 1$ fossil fuel emission data set for carbonaceous aerosol and implementation and radiative impact in the ECHAM4 model, Journal of Geophysical Research: Atmospheres, 104, 22137-22162, 1999.

Crutzen, P. J., and Andreae, M. O.: Biomass burning in the tropics: impact on atmospheric chemistry and biogeochemical cycles, Science, 250, 1669-1678, 1990.

Dee, D., and Uppala, S.: Variational bias correction of satellite radiance data in the ERA-Interim reanalysis, Quarterly Journal of the Royal Meteorological Society, 135, 1830-1841, 2009.

Dee, D., Uppala, S., Simmons, A., Berrisford, P., Poli, P., Kobayashi, S., Andrae, U., Balmaseda, M., Balsamo, G., and Bauer, P.: The ERA-Interim reanalysis: Configuration and performance of the data assimilation system, Quarterly Journal of the royal meteorological society, 137, 553-597, 2011.

Delle Monache, L., and Stull, R. B.: An ensemble air-quality forecast over western Europe during an ozone episode, Atmospheric Environment, 37, 3469-3474, http://dx.doi.org/10.1016/S1352-2310(03)00475-8, 2003.

Diallo, M., Legras, B., and Chédin, A.: Age of stratospheric air in the ERA-Interim, Atmospheric Chemistry and Physics, 12, 12133-12154, 2012.

Djalalova, I., J. Wilczak, S. McKeen, G. Grell, S. Peckham, M. Pagowski, L. DelleMonache, J. McQueen, Y. Tang and P. Lee (2010). "Ensemble and bias-correction techniques for air 
quality model forecasts of surface $\mathrm{O}_{3}$ and $\mathrm{PM}_{2.5}$ during the TEXAQS-II experiment of 2006." Atmospheric Environment 44(4): 455-467.

Fast, J. D., Gustafson, W. I., Easter, R. C., Zaveri, R. A., Barnard, J. C., Chapman, E. G., Grell, G. A., and Peckham, S. E.: Evolution of ozone, particulates, and aerosol direct radiative forcing in the vicinity of Houston using a fully coupled meteorology-chemistry-aerosol model, Journal of Geophysical Research, 111, 10.1029/2005jd006721, 2006.

Forkel, R., Balzarini, A., Baró, R., Bianconi, R., Curci, G., Jiménez-Guerrero, P., Hirtl, M., Honzak, L., Lorenz, C., and Im, U.: Analysis of the WRF-Chem contributions to AQMEII phase2 with respect to aerosol radiative feedbacks on meteorology and pollutant distributions, Atmospheric Environment, 115, 630-645, 2015.

Galmarini, S., Bianconi, R., Addis, R., Andronopoulos, S., Astrup, P., Bartzis, J. C., Bellasio, R., Buckley, R., Champion, H., Chino, M., D’Amours, R., Davakis, E., Eleveld, H., Glaab, H., Manning, A., Mikkelsen, T., Pechinger, U., Polreich, E., Prodanova, M., Slaper, H., Syrakov, D., Terada, H., and Van der Auwera, L.: Ensemble dispersion forecasting-Part II: application and evaluation, Atmospheric Environment, 38, 4619-4632, http://dx.doi.org/10.1016/j.atmosenv.2004.05.031, 2004a.

Galmarini, S., Bianconi, R., Klug, W., Mikkelsen, T., Addis, R., Andronopoulos, S., Astrup, P., Baklanov, A., Bartniki, J., Bartzis, J. C., Bellasio, R., Bompay, F., Buckley, R., Bouzom, M., Champion, H., D’Amours, R., Davakis, E., Eleveld, H., Geertsema, G. T., Glaab, H., Kollax, M., Ilvonen, M., Manning, A., Pechinger, U., Persson, C., Polreich, E., Potemski, S., Prodanova, M., Saltbones, J., Slaper, H., Sofiev, M. A., Syrakov, D., Sørensen, J. H., Auwera, L. V. d., Valkama, I., and Zelazny, R.: Ensemble dispersion forecasting-Part I: concept, approach and indicators, Atmospheric Environment, 38, 4607-4617, http://dx.doi.org/10.1016/j.atmosenv.2004.05.030, 2004 b.

Ge, C., Wang, J., and Reid, J. S.: Mesoscale modeling of smoke transport over the Southeast Asian Maritime Continent: coupling of smoke direct radiative effect below and above the low-level clouds, Atmospheric Chemistry and Physics, 14, 159-174, 10.5194/acp-14-1592014, 2014.

Grell, G., and Baklanov, A.: Integrated modeling for forecasting weather and air quality: A call for fully coupled approaches, Atmospheric Environment, 45, 6845-6851, 2011.

Grell, G. A., and Dévényi, D.: A generalized approach to parameterizing convection combining ensemble and data assimilation techniques, Geophysical Research Letters, 29, 2002.

Grell, G. A., Peckham, S. E., Schmitz, R., McKeen, S. A., Frost, G., Skamarock, W. C., and Eder, B.: Fully coupled "online" chemistry within the WRF model, Atmospheric Environment, 39, 6957-6975, 10.1016/j.atmosenv.2005.04.027, 2005.

Guenther, A., Hewitt, C. N., Erickson, D., Fall, R., Geron, C., Graedel, T., Harley, P., Klinger, L., Lerdau, M., and McKay, W.: A global model of natural volatile organic compound emissions, Journal of Geophysical Research: Atmospheres, 100, 8873-8892, 1995. 
Hogan, T. F., and Rosmond, T. E.: The description of the Navy Operational Global Atmospheric Prediction System's spectral forecast model, Monthly Weather Review, 119, 1786-1815, 1991.

Holben, B. N., Eck, T., Slutsker, I., Tanre, D., Buis, J., Setzer, A., Vermote, E., Reagan, J. A., Kaufman, Y., and Nakajima, T.: AERONET-A federated instrument network and data archive for aerosol characterization, Remote sensing of environment, 66, 1-16, 1998.

Hou, A., R. Kakar, S. Neeck, A. Azarbarzin, C. Kummerow, M. Kojima, R. Oki, K. Nakamura, and T. Iguchi, 2014: The Global Precipitation Measurement Mission. Bull. Amer. Meteor. Soc., 95, 701-722, doi: 10.1175/BAMS-D-13-00164.1.

Hyer, E. J., and Chew, B. N.: Aerosol transport model evaluation of an extreme smoke episode in Southeast Asia, Atmospheric Environment, 44, 1422-1427, 2010.

Hyer, E. J., Reid, J. S., Prins, E. M., Hoffman, J. P., Schmidt, C. C., Miettinen, J. I., and Giglio, L.: Patterns of fire activity over Indonesia and Malaysia from polar and geostationary satellite observations, Atmospheric Research, 122, 504-519, 2013.

Janjic, Z. I.: The step-mountain eta coordinate model: Further developments of the convection, viscous sublayer, and turbulence closure schemes, Monthly Weather Review, 122, 927945, 1994.

Joyce, R. J., Janowiak, J. E., Arkin, P. A., and Xie, P.: CMORPH: A method that produces global precipitation estimates from passive microwave and infrared data at high spatial and temporal resolution, Journal of Hydrometeorology, 5, 487-503, 2004.

Justice, C., Giglio, L., Korontzi, S., Owens, J., Morisette, J., Roy, D., Descloitres, J., Alleaume, S., Petitcolin, F., and Kaufman, Y.: The MODIS fire products, Remote Sensing of Environment, 83, 244-262, 2002.

Kalnay, E.: Atmospheric modeling, data assimilation and predictability, Cambridge University Press, New York, USA, 364 pp., 2002.

Kaufman, Y., Ichoku, C., Giglio, L., Korontzi, S., Chu, D., Hao, W., Li, R.-R., and Justice, C.: Fire and smoke observed from the Earth Observing System MODIS instrument-products, validation, and operational use, International Journal of Remote Sensing, 24, 1765-1781, 2003.

Lin, Y.-L., Farley, R. D., and Orville, H. D.: Bulk parameterization of the snow field in a cloud model, Journal of Climate and Applied Meteorology, 22, 1065-1092, 1983.

Lynch, P., Reid, J. S., Westphal, D. L., Hogan, T. F., Hyer, E. J., Curtis, C. A., Hegg, D. A., Campbell, J. R., Rubin, J. I., Sessions, W. R., and Turk, F. J.: An 11-year global gridded aerosol optical thickness reanalysis (v1.0) for atmospheric and climate sciences, Geoscientific Model Development, 9, 1489, 2016.

Mallet, V., and Sportisse, B.: Uncertainty in a chemistry-transport model due to physical parameterizations and numerical approximations: An ensemble approach applied to ozone modeling, Journal of Geophysical Research, 111, 10.1029/2005jd006149, 2006.

McKeen, S., Chung, S. H., Wilczak, J., Grell, G., Djalalova, I., Peckham, S., Gong, W., Bouchet, V., Moffet, R., Tang, Y., Carmichael, G. R., Mathur, R., and Yu, S.: Evaluation of 
several PM2.5forecast models using data collected during the ICARTT/NEAQS 2004

field study, Journal of Geophysical Research, 112, 10.1029/2006jd007608, 2007.

National Centers for Environmental Prediction/National Weather Service/NOAA/U.S.

Department of Commerce (1997), NCEP FNL Operational Model Global Tropospheric

Analyses, April 1997 through June 2007, https://doi.org/10.5065/D6FB50XD, Research

Data Archive at the National Center for Atmospheric Research, Computational and

Information Systems Laboratory, Boulder, Colo. Accessed $\dagger 1122014$.

Nasrollahi, N., AghaKouchak, A., Li, J., Gao, X., Hsu, K., and Sorooshian, S.: Assessing the impacts of different WRF precipitation physics in hurricane simulations, Weather and Forecasting, 27, 1003-1016, 2012.

O'Neill, N. T.: Spectral discrimination of coarse and fine mode optical depth, Journal of Geophysical Research, 108, 10.1029/2002jd002975, 2003.

Olivier, J. G., Bouwman, A., Berdowski, J., Veldt, C., Bloos, J., Visschedijk, A., Zandveld, P., and Haverlag, J.: Description of EDGAR Version 2.0: A set of global emission inventories of greenhouse gases and ozone-depleting substances for all anthropogenic and most natural sources on a per country basis and on 1 degree $\mathrm{x} 1$ degree grid, 1996.

Reid, J., Xian, P., Hyer, E., Flatau, M., Ramirez, E., Turk, F., Sampson, C., Zhang, C., Fukada, E., and Maloney, E.: Multi-scale meteorological conceptual analysis of observed active fire hotspot activity and smoke optical depth in the Maritime Continent, Atmospheric Chemistry and Physics, 12, 2117-2147, 2012.

Reid, J. S., Hyer, E. J., Prins, E. M., Westphal, D. L., Zhang, J., Wang, J., Christopher, S. A., Curtis, C. A., Schmidt, C. C., Eleuterio, D. P., Richardson, K. A., and Hoffman, J. P.: Global Monitoring and Forecasting of Biomass-Burning Smoke: Description of and Lessons From the Fire Locating and Modeling of Burning Emissions (FLAMBE) Program, IEEE Journal of Selected Topics in Applied Earth Observations and Remote Sensing, 2, 144-162, 10.1109/jstars.2009.2027443, 2009.

Reid, J. S., Hyer, E. J., Johnson, R. S., Holben, B. N., Yokelson, R. J., Zhang, J., Campbell, J. R., Christopher, S. A., Di Girolamo, L., Giglio, L., Holz, R. E., Kearney, C., Miettinen, J., Reid, E. A., Turk, F. J., Wang, J., Xian, P., Zhao, G., Balasubramanian, R., Chew, B. N., Janjai, S., Lagrosas, N., Lestari, P., Lin, N.-H., Mahmud, M., Nguyen, A. X., Norris, B., Oanh, N. T. K., Oo, M., Salinas, S. V., Welton, E. J., and Liew, S. C.: Observing and understanding the Southeast Asian aerosol system by remote sensing: An initial review and analysis for the Seven Southeast Asian Studies (7SEAS) program, Atmospheric Research, 122, 403-468, 10.1016/j.atmosres.2012.06.005, 2013.

Reid, J. S., Lagrosas, N. D., Jonsson, H. H., Reid, E. A., Sessions, W. R., Simpas, J. B., Uy, S. N., Boyd, T. J., Atwood, S. A., Blake, D. R., Campbell, J. R., Cliff, S. S., Holben, B. N., Holz, R. E., Hyer, E. J., Lynch, P., Meinardi, S., Posselt, D. J., Richardson, K. A., Salinas, S. V., Smirnov, A., Wang, Q., Yu, L., and Zhang, J.: Observations of the temporal variability in aerosol properties and their relationships to meteorology in the summer monsoonal South China Sea/East Sea: the scale-dependent role of monsoonal 
flows, the Madden-Julian Oscillation, tropical cyclones, squall lines and cold pools, Atmospheric Chemistry and Physics, 15, 1745-1768, 10.5194/acp-15-1745-2015, 2015.

Rosenfeld, D., and Woodley, W.: Convective Clouds with Sustained Highly Supercooled Liquid Water Until-38oC, Nature, 2000.

Rubin, J. I., Reid, J. S., Hansen, J. A., Anderson, J. L., Hoar, T. J., Reynolds, C. A., Sessions, W. R., and Westphal, D. L.: Development of the Ensemble Navy Aerosol Analysis Prediction System (ENAAPS) and its application of the Data Assimilation Research Testbed (DART) in support of aerosol forecasting, Atmospheric Chemistry and Physics, 16, 3927, 2016.

Saide, P., Spak, S., Pierce, R., Otkin, J., Schaack, T., Heidinger, A., Silva, A., Kacenelenbogen, M., Redemann, J., and Carmichael, G.: Central American biomass burning smoke can increase tornado severity in the US, Geophysical Research Letters, 42, 956-965, 2015.

Schell, B., Ackermann, I. J., Hass, H., Binkowski, F. S., and Ebel, A.: Modeling the formation of secondary organic aerosol within a comprehensive air quality model system, J. Geophys. Res., 106, 28275-28293, doi:10.1029/2001JD000384, 2001.

Van Der Werf, G. R., Randerson, J. T., Giglio, L., Gobron, N., and Dolman, A.: Climate controls on the variability of fires in the tropics and subtropics, Global Biogeochemical Cycles, 22, 2008.

Wałaszek, K., Kryza, M., and Werner, M.: Evaluation of the WRF meteorological model results during a high ozone episode in SW Poland-the role of model initial conditions, International Journal of Environment and Pollution 15, 54, 193-202, 2014.

Wang, J., Ge, C., Yang, Z., Hyer, E. J., Reid, J. S., Chew, B.-N., Mahmud, M., Zhang, Y., and Zhang, M.: Mesoscale modeling of smoke transport over the Southeast Asian Maritime Continent: Interplay of sea breeze, trade wind, typhoon, and topography, Atmospheric Research, 122, 486-503, 10.1016/j.atmosres.2012.05.009, 2013.

Wiedinmyer, C., Akagi, S., Yokelson, R. J., Emmons, L., Al-Saadi, J., Orlando, J., and Soja, A.: The Fire INventory from NCAR (FINN): a high resolution global model to estimate the emissions from open burning, Geoscientific Model Development, 4, 625, 2011.

Winker, D. M., Pelon, J., Coakley, J. A., Ackerman, S. A., Charlson, R. J., Colarco, P. R., Flamant, P., Fu, Q., Hoff, R. M., Kittaka, C., Kubar, T. L., Le Treut, H., McCormick, M. P., Mégie, G., Poole, L., Powell, K., Trepte, C., Vaughan, M. A., and Wielicki, B. A.: The CALIPSO Mission: A Global 3D View of Aerosols and Clouds, Bulletin of the American Meteorological Society, 91, 1211-1229, 10.1175/2010BAMS3009.1, 2010.

Xian, P., Reid, J. S., Atwood, S. A., Johnson, R. S., Hyer, E. J., Westphal, D. L., and Sessions, W.: Smoke aerosol transport patterns over the Maritime Continent, Atmospheric

Research, 122, 469-485, 2013.

Yang, Q., Gustafson Jr, W., Fast, J. D., Wang, H., Easter, R. C., Morrison, H., Lee, Y.-N., Chapman, E. G., Spak, S., and Mena-Carrasco, M.: Assessing regional scale predictions of aerosols, marine stratocumulus, and their interactions during VOCALS-REx using WRF-Chem, Atmospheric Chemistry and Physics, 11, 11951-11975, 2011. 
Zhang, Q., Streets, D. G., Carmichael, G. R., He, K., Huo, H., Kannari, A., Klimont, Z., Park, I., Reddy, S., and Fu, J.: Asian emissions in 2006 for the NASA INTEX-B mission, Atmospheric Chemistry and Physics, 9, 5131-5153, 2009.

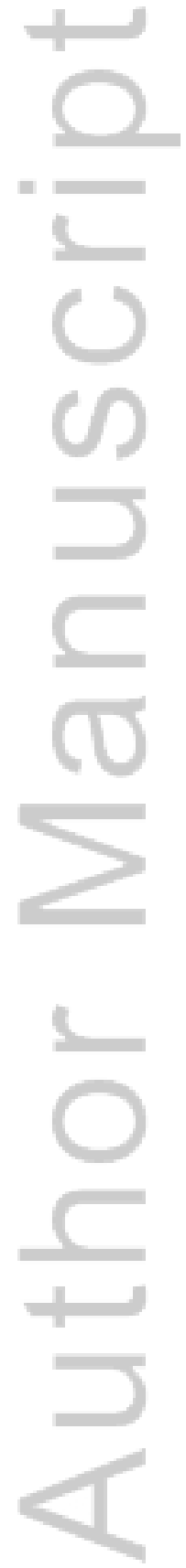


(a)

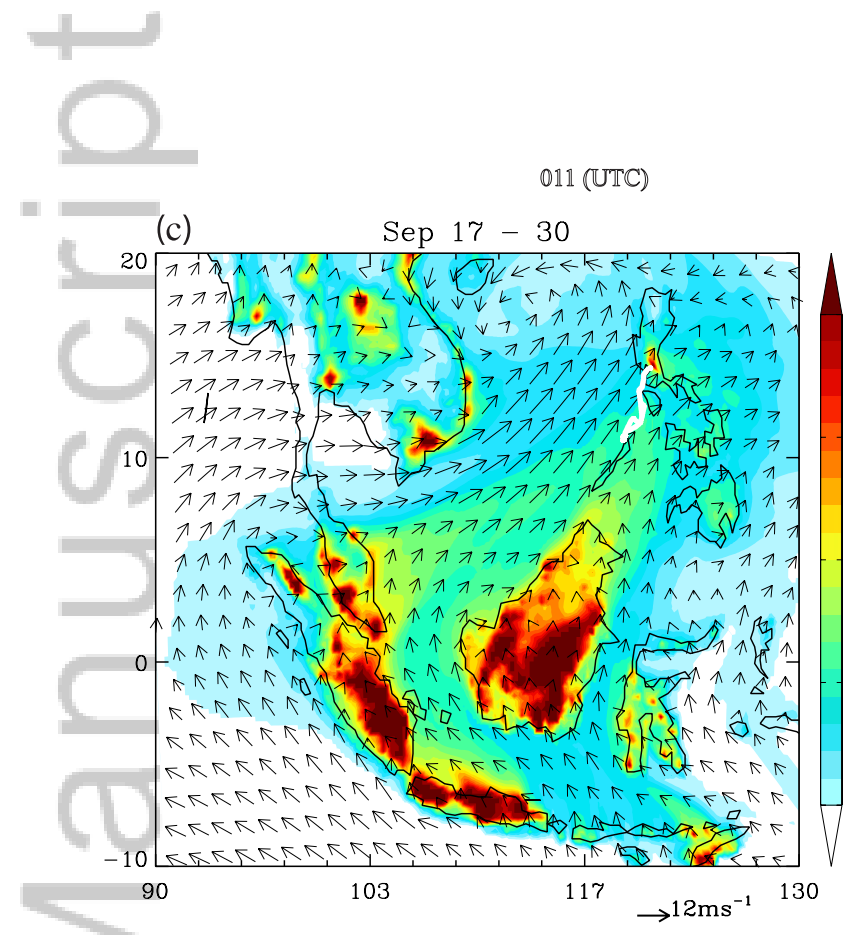

(d)

(e)

Figure 1: (a) Ensemble simulated and Vasco measured $\mathrm{PM}_{2.5}$, (b) similar as (a) but the ensemble 2 simulations after Sep. 29 are maximum values from $50 \mathrm{~km}$ radius centered at certain model grid box (c) averaged $\mathrm{PM}_{2.5}$ map during 17 - 31 September 2011, (d) AERONET and simulated AOD at Kuching, and exclude the data after September 28, (e) similar as (d) but at Singapore. The numbers in (c) are 1-South China Sea, 2-Vasco, 3-Philippines, 4-Sumatra, 5Singapore, 6-Kuching, 7-Borneo. The error bars of time series represent the standard deviation of the ensemble means.

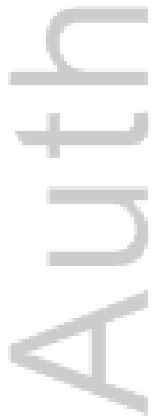


(a) Vasco
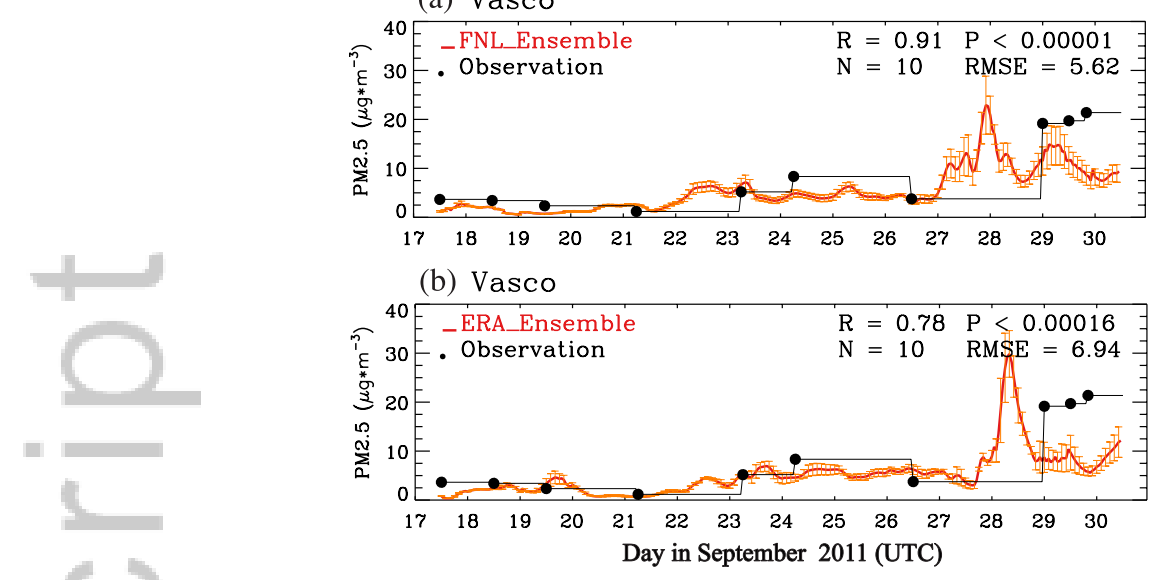

(c)

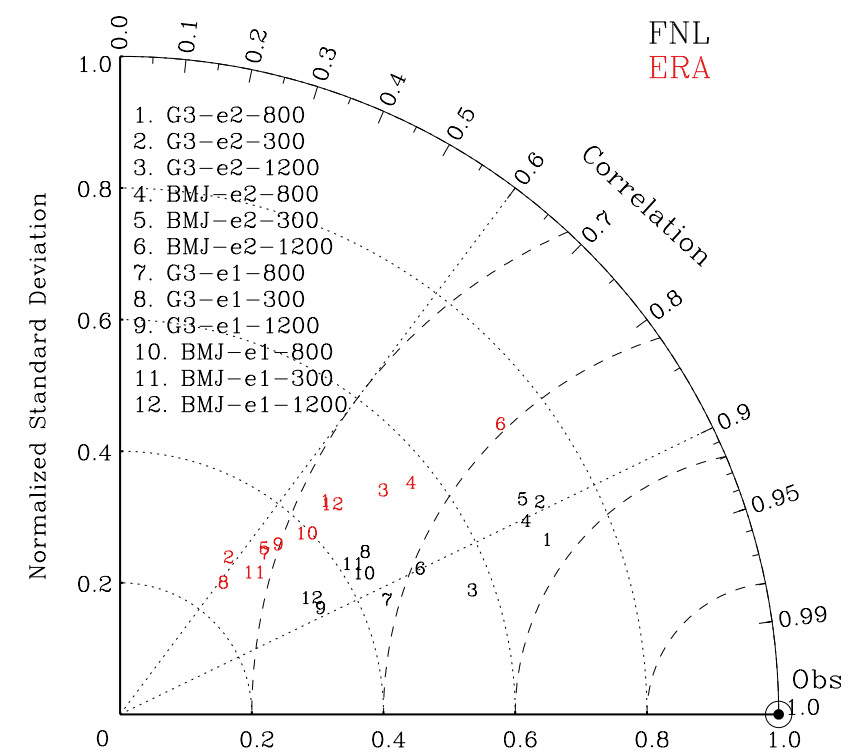

Figure 2: Ensemble simulated $\mathrm{PM}_{2.5}$ from different meteorological initial and boundary conditions (a) FNL, (b) ERA, (c) Taylor diagram for the model evaluations comparing against Vasco cruise $\mathrm{PM}_{2.5}$ observations. The same numbers are pairs with same simulation configurations. Black dots and red dots are from FNL and ERA respectively. The error bars of time series represent the standard deviation of the ensemble means.

This article is protected by copyright. All rights reserved. 
FNL

(a) 09-27_12:00

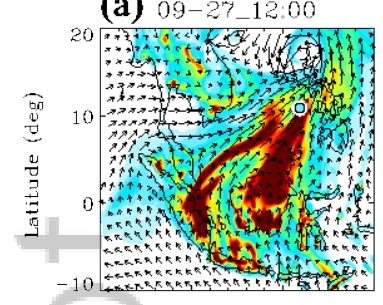

ERA

(e) $09-27-12: 00$

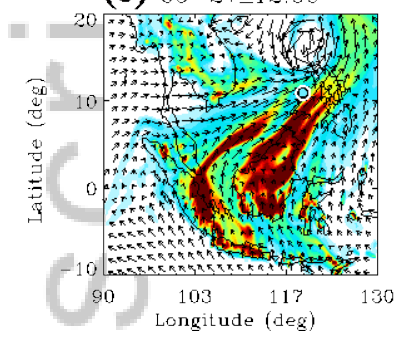

(b) 09-28_00:00

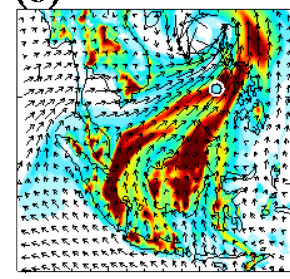

(f) 09-28_00:00

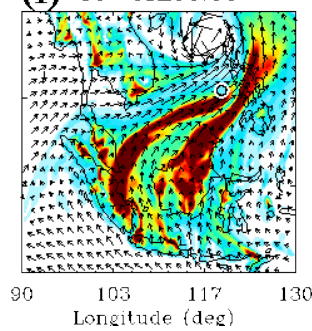

(c) $09-28-12.00$

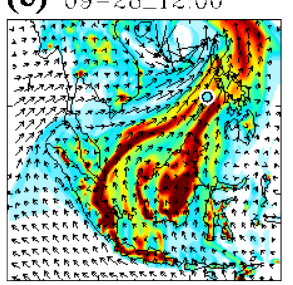

(g) 09-28_12:00

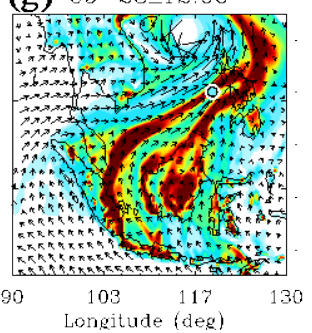

(d) 09-29_00:00

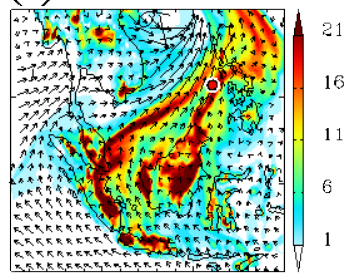

(h) 09-29_00:00

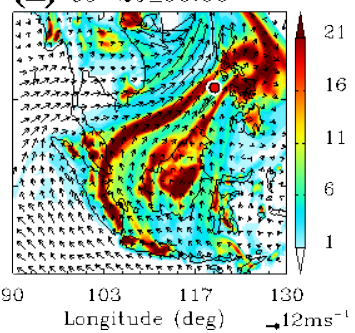

Figure 3: Simulated PM 2.5 with G3-e2-800 during September 27 12:00 - 29 00:00 UTC of 2011. Solid circle on each panel shows the location of Vasco and is color-coded on the same color scheme as that used for the color-filled contour of modeled smoke concentration. 

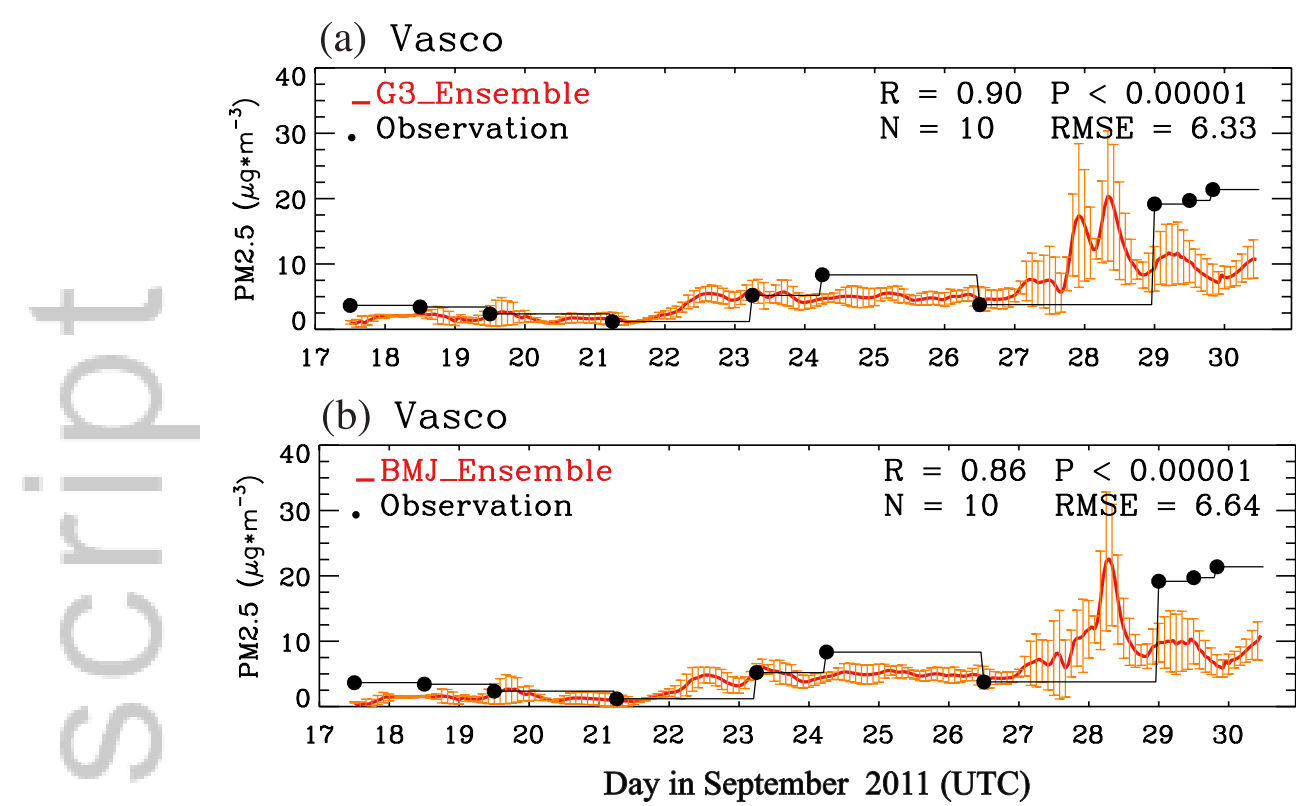

Figure 4: Ensemble simulated $\mathrm{PM}_{2.5}$ from different cumulus parameters (a) G3, (b) BMJ. The error bars of time series represent the standard deviation of the ensemble means.

This article is protected by copyright. All rights reserved. 

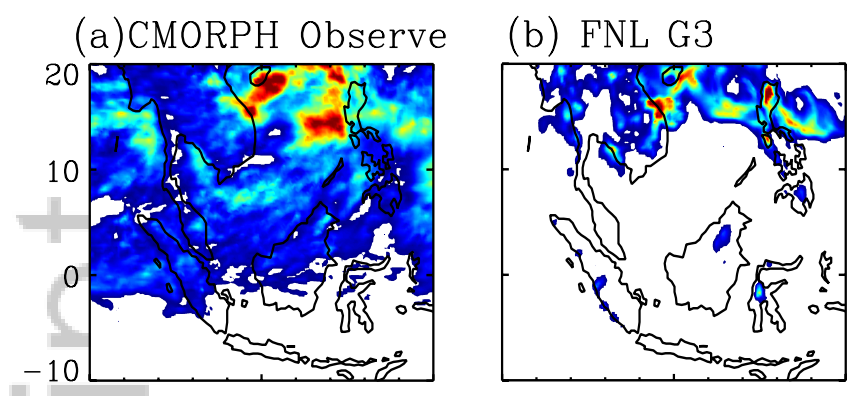

(c) FNL BMJ
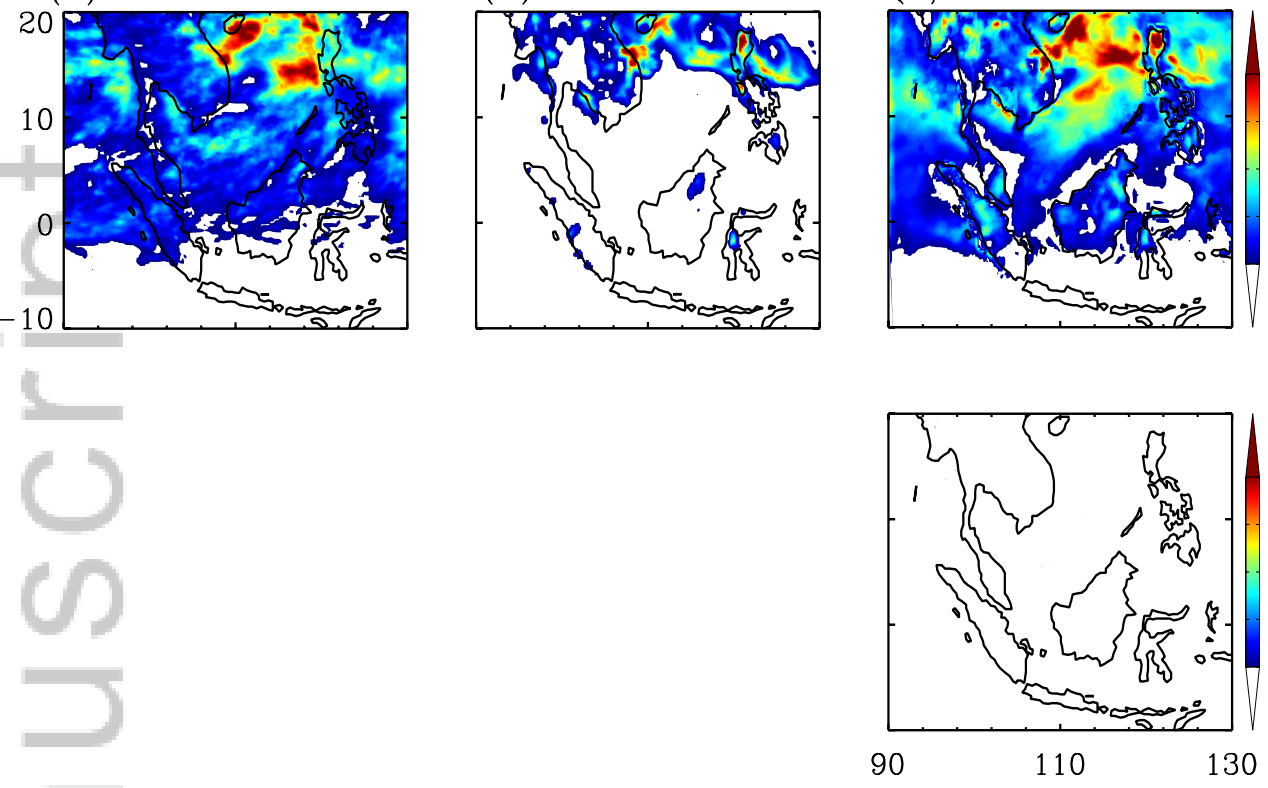

Figure 5: Observed and simulated averaged hourly precipitation during September 17 - 30 of 2011.

This article is protected by copyright. All rights reserved. 

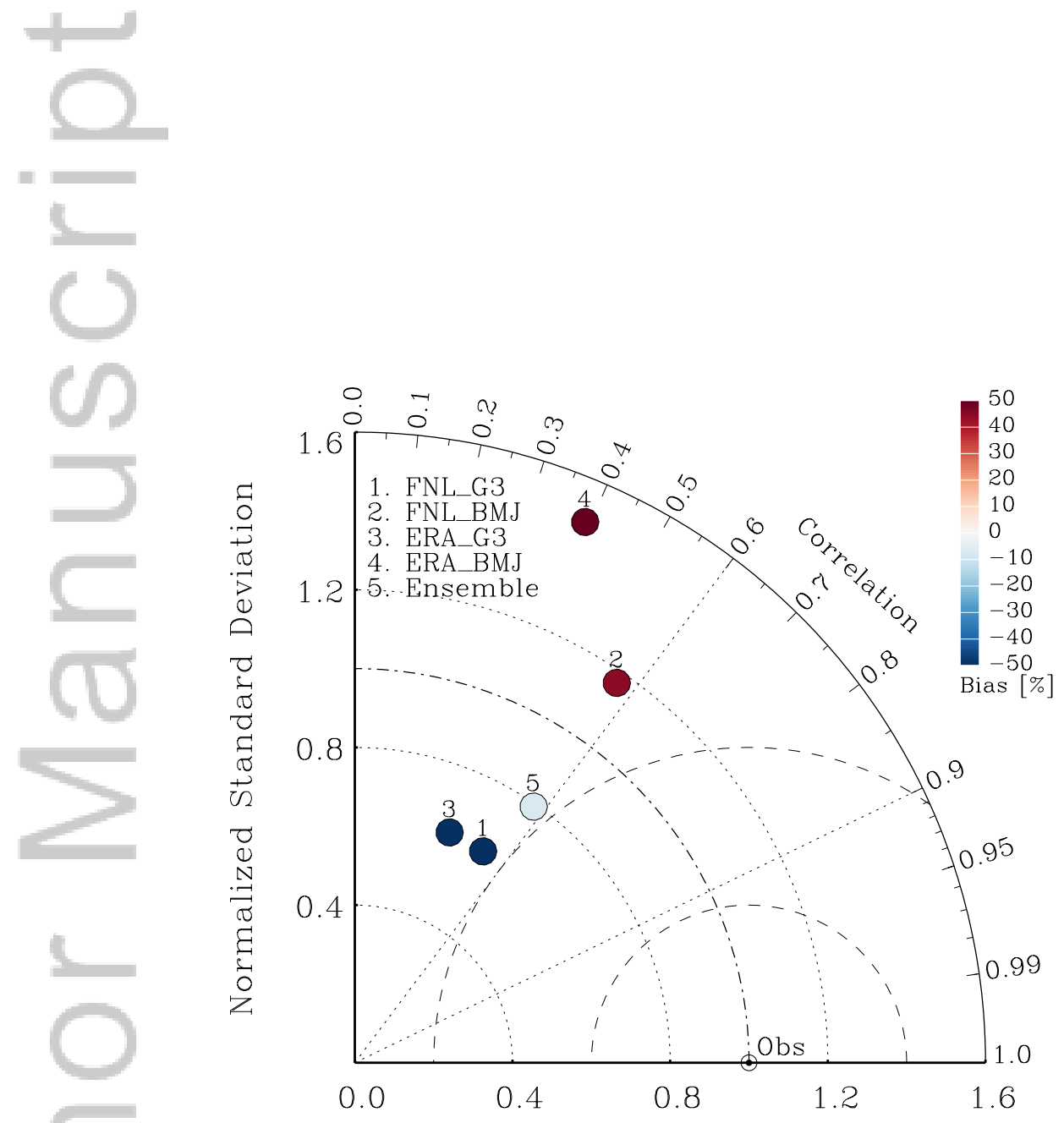

Figure 6: Taylor diagram for the model evaluations comparing against CMORPHY precipitation.

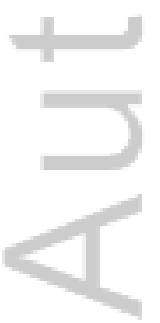




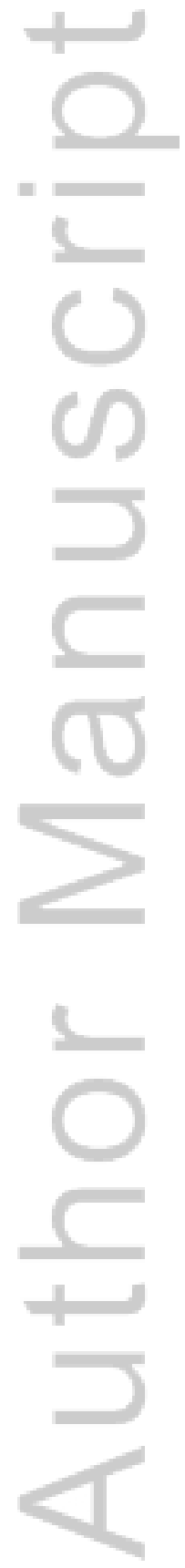

This article is protected by copyright. All rights reserved. 

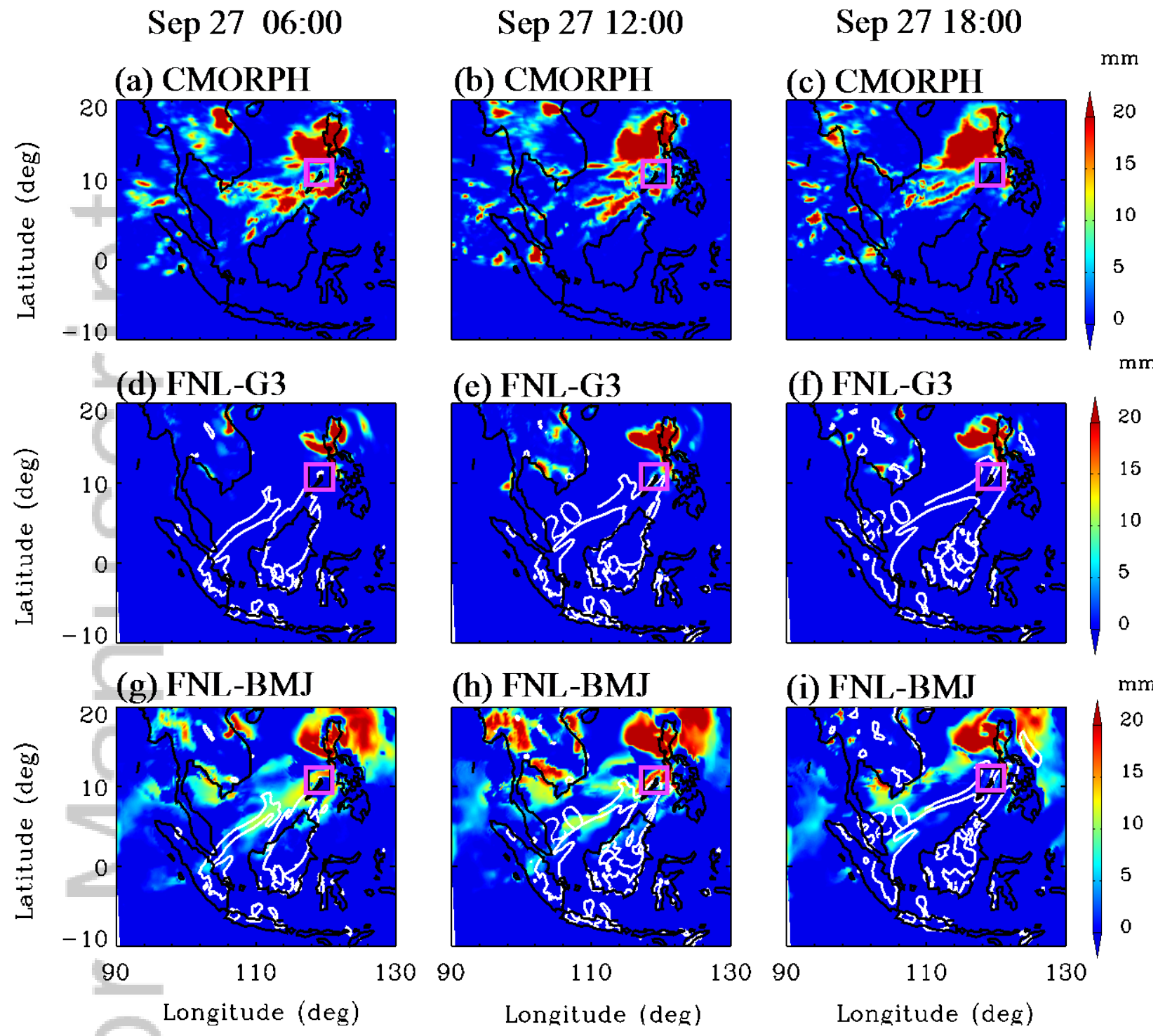

(h) FNL-BMJ

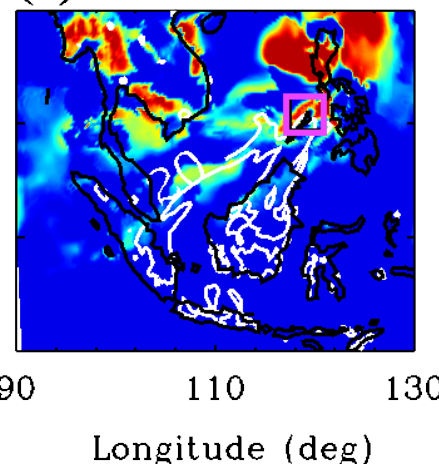

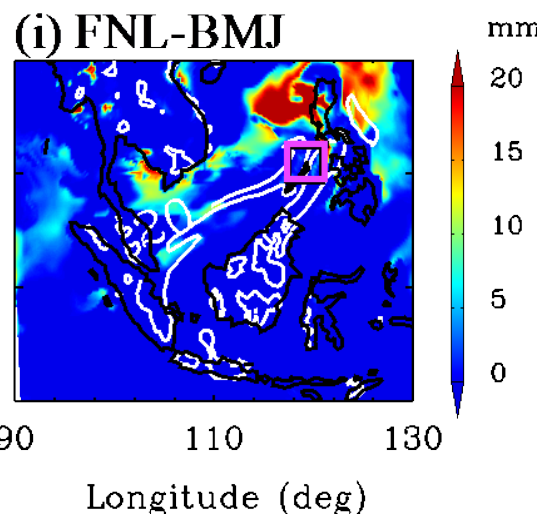

Figure 7: Uncertainty from cumulus scheme. Simulated $\mathrm{PM}_{2.5}$ during September 27 06:00 - 27 18:00 UTC of 2011. The color-filled contour is 6-hour total precipitation, and the white contour line is for $\mathrm{PM}_{2.5}$ is $20 \mu \mathrm{g} \mathrm{m}^{-3}$. The Vasco place is denoted as pink square in each panel.

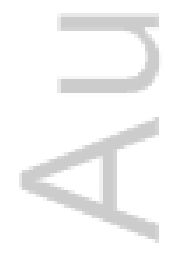



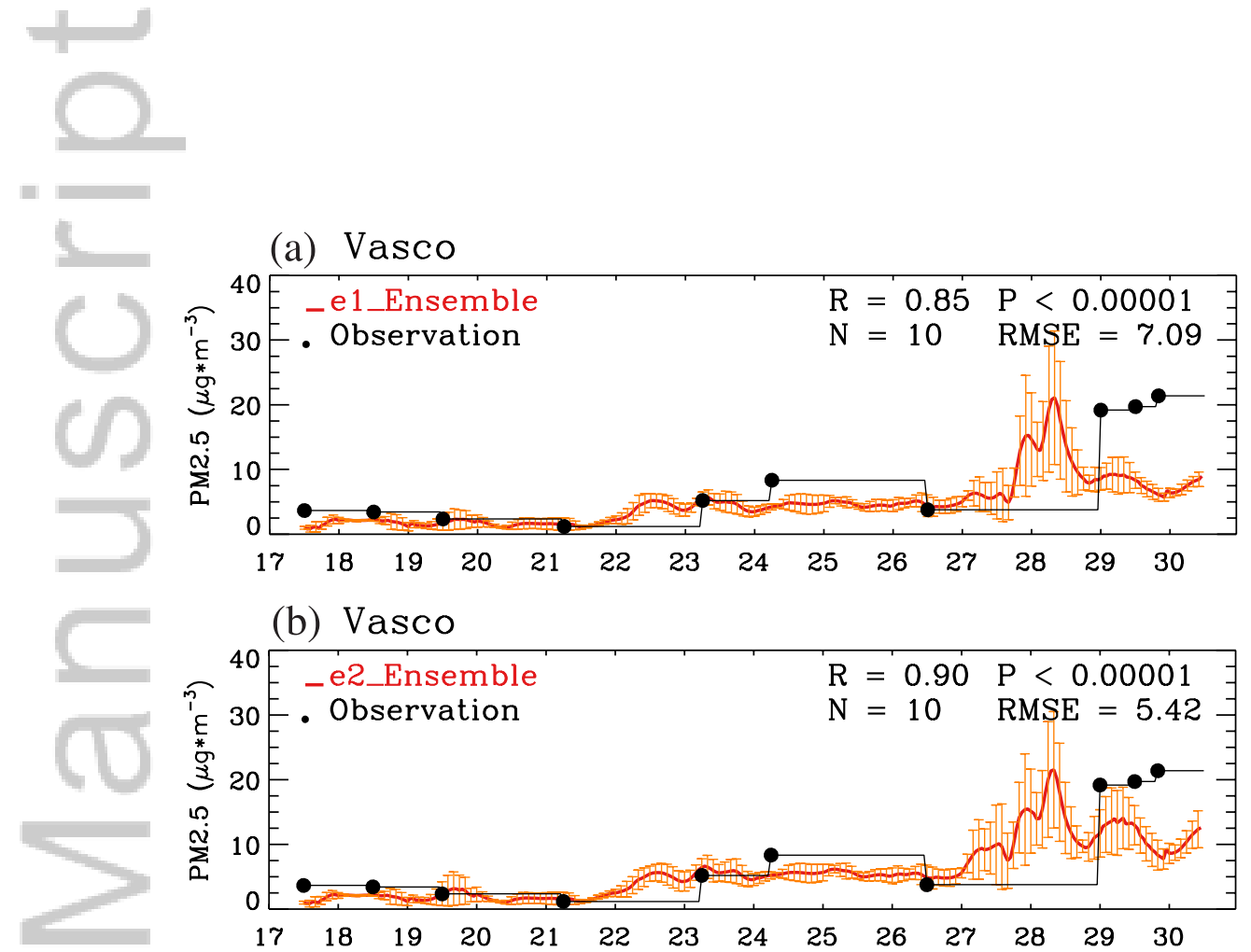

(b) Vasco

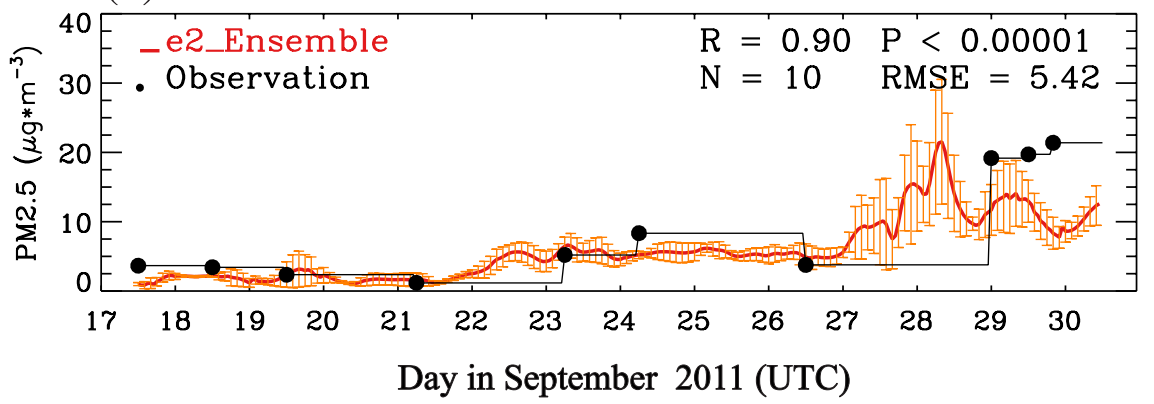

Figure 8: Ensemble simulated $\mathrm{PM}_{2.5}$ from different emissions (a) emission e1 - old version of FLAMBE emissions, (b) emission e2 - new version of FLAMBE emissions. The error bars of time series represent the standard deviation of the ensemble means.

This article is protected by copyright. All rights reserved. 


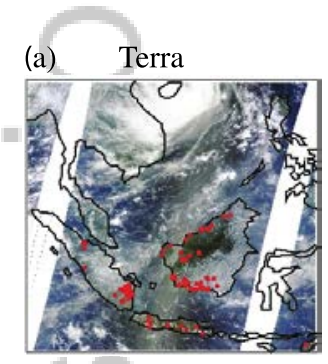

(e) Terra AOD (b)

Aqua

(f) Aqua AOD

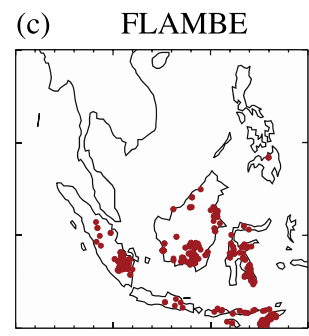

(g) Simulated AOD (d) Updated FLAMBE

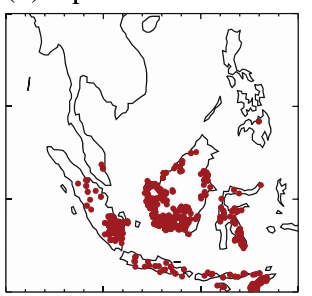

(h) $\underset{0.0}{\operatorname{Simulated}} \underset{0.2}{\mathrm{AOOD}} \underset{0.6}{0.8}$ with update

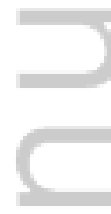

$\circ$

Figure 9: For September 29 of 2011, (a) True color image from Terra, (b) True color image from Aqua, (c) FLAMBE two days' maximum fire emissions, (d) Updated fire emission according to the fire spots from Terra and Aqua, (e) Terra AOD, (f) Aqua AOD, (g) simulated AOD, (h) simulated AOD with updated fire emissions. The colored dot represents. Solid circle on $(\mathrm{g})$ and (h) shows AERONET AOD over Kuching and is color-coded on the same color scheme as that used for the color-filled contour of modeled AOD. 
(a) Vasco

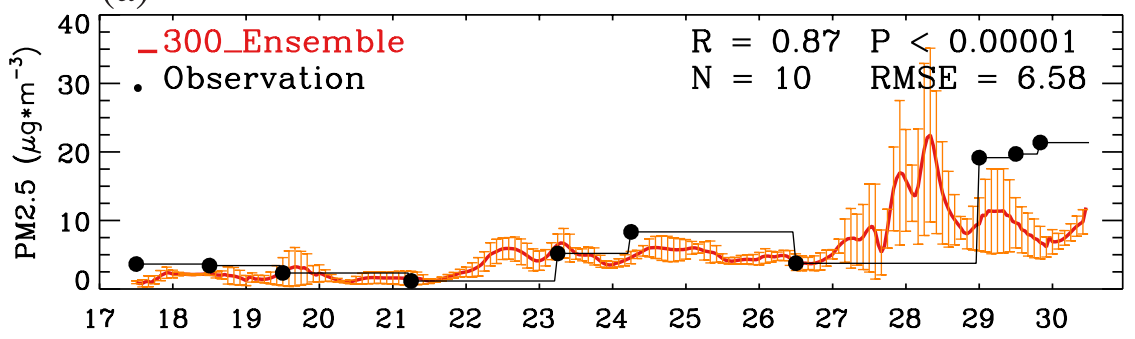

(b) Vasco

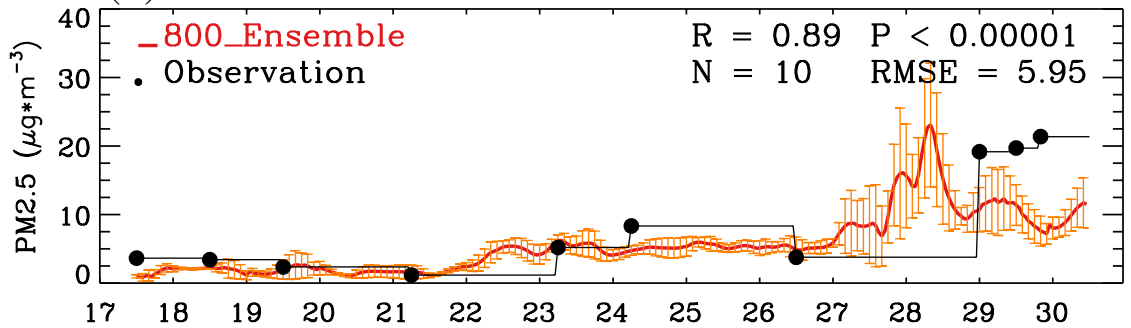

(c) Vasco

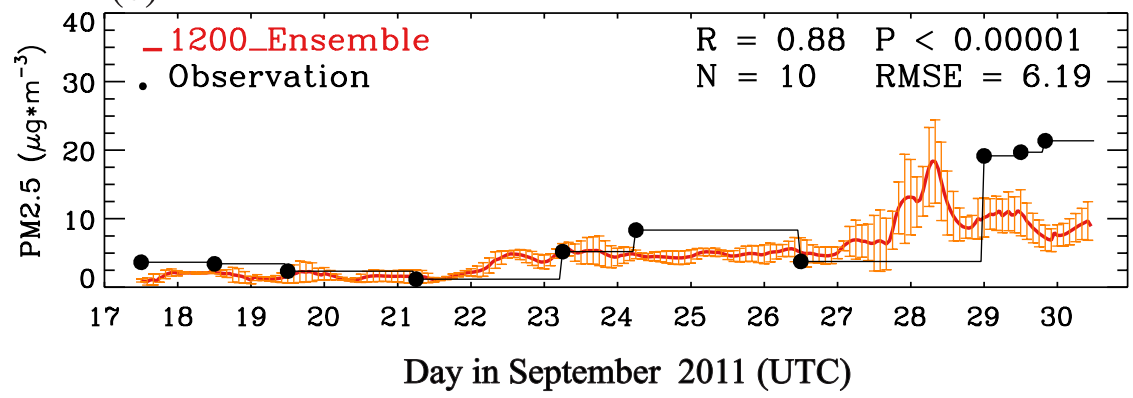

This article is protected by copyright. All rights reserved. 
Figure 10: Ensemble simulated $\mathrm{PM}_{2.5}$ from different injection heights (a) $300 \mathrm{~m}$, (b) $800 \mathrm{~m}$, (c) $1200 \mathrm{~m}$. The error bars of time series represent the standard deviation of the ensemble means.

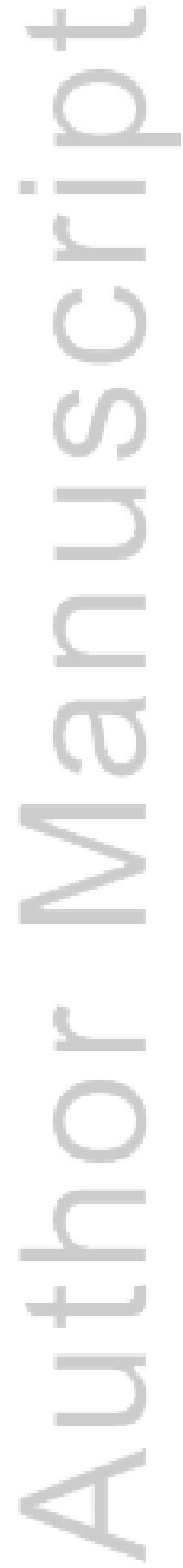




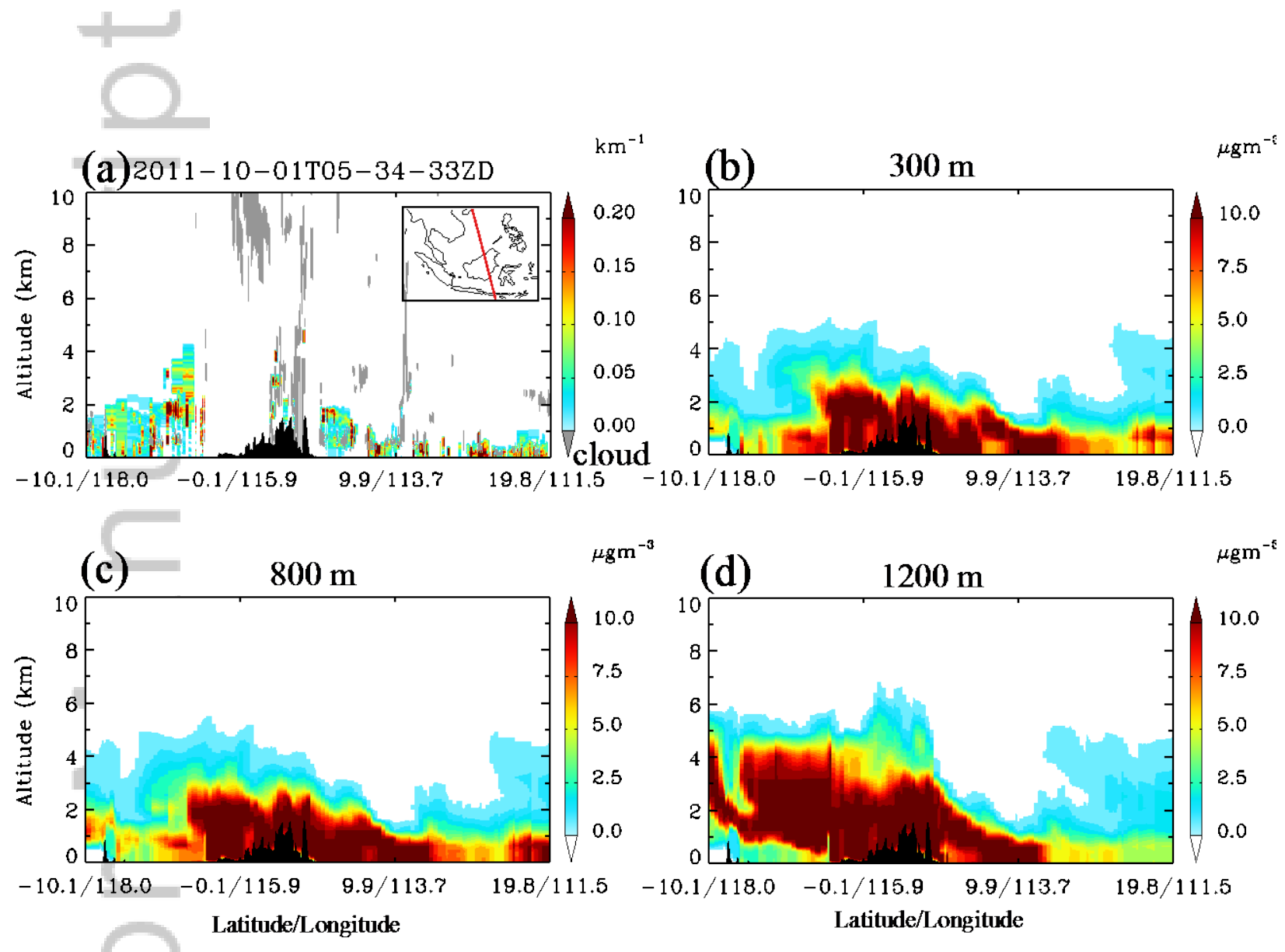

Figure 11: Inter-comparison of CALIOP-derived vertical profile of aerosol extinction coefficient (a) with the WRF-Chem simulated vertical profile of smoke concentration along the corresponding CALIPSO ground track of October 1, 2011. The model results are from the simulation that set the smoke injection height at $300 \mathrm{~m}(\mathrm{~b}), 800 \mathrm{~m}$ (c) and $1200 \mathrm{~m}(\mathrm{~d})$. Terrain is black shaded in each panel. 

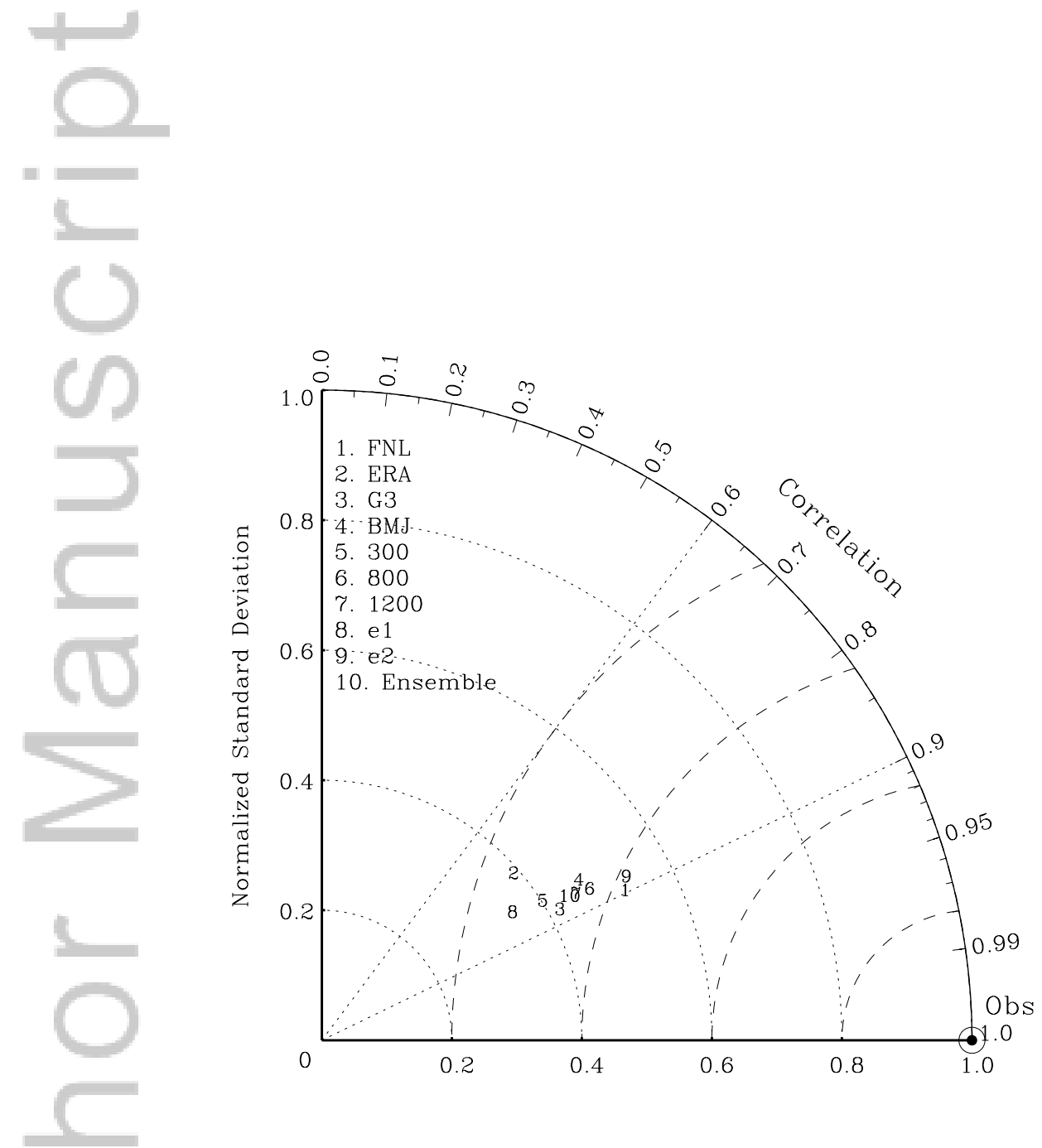

Figure 12: Taylor diagram of the model evaluations comparing against Vasco $\mathrm{PM}_{2.5}$ observations for simulated $\mathrm{PM}_{2.5}$ from different ensemble subgroups (1-9). 

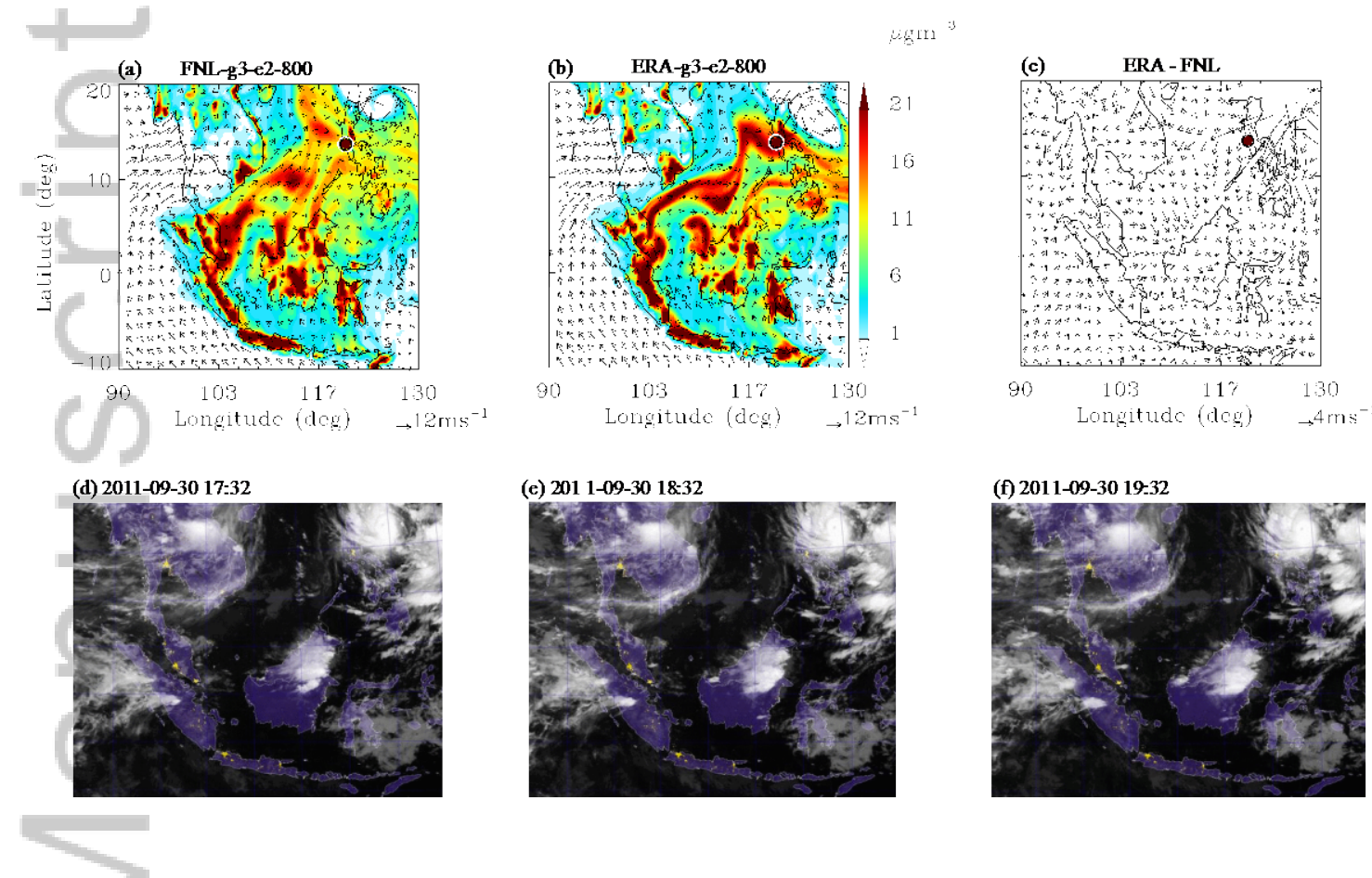

Figure 13: Sep 30 18:00 (a) PM$_{2.5}$ simulated by FNL-g3-e2-800, (b) PM 2.5 simulated by ERA-g3e2-800, (c) Wind difference between ERA simulation and FNL simulation, (d) Cloud image of 2011 Sep 30 17:32, (e) Cloud image of 2011 Sep 30 18:32, (f) Cloud image of 2011 Sep 30 19:32. 
(a) Vasco

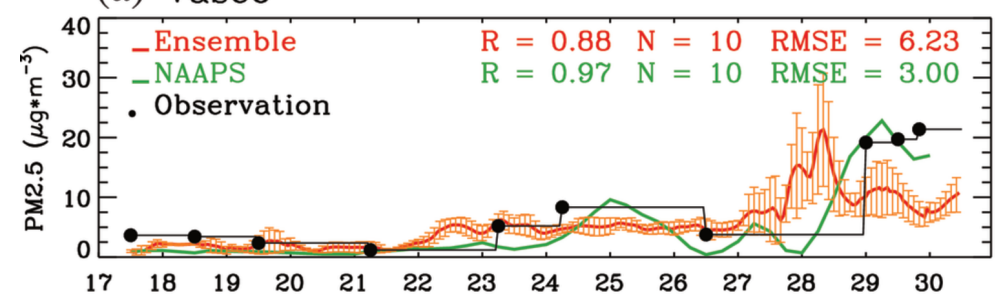

Day in September 2011 (UTC)

(c)

Sep $17-30$

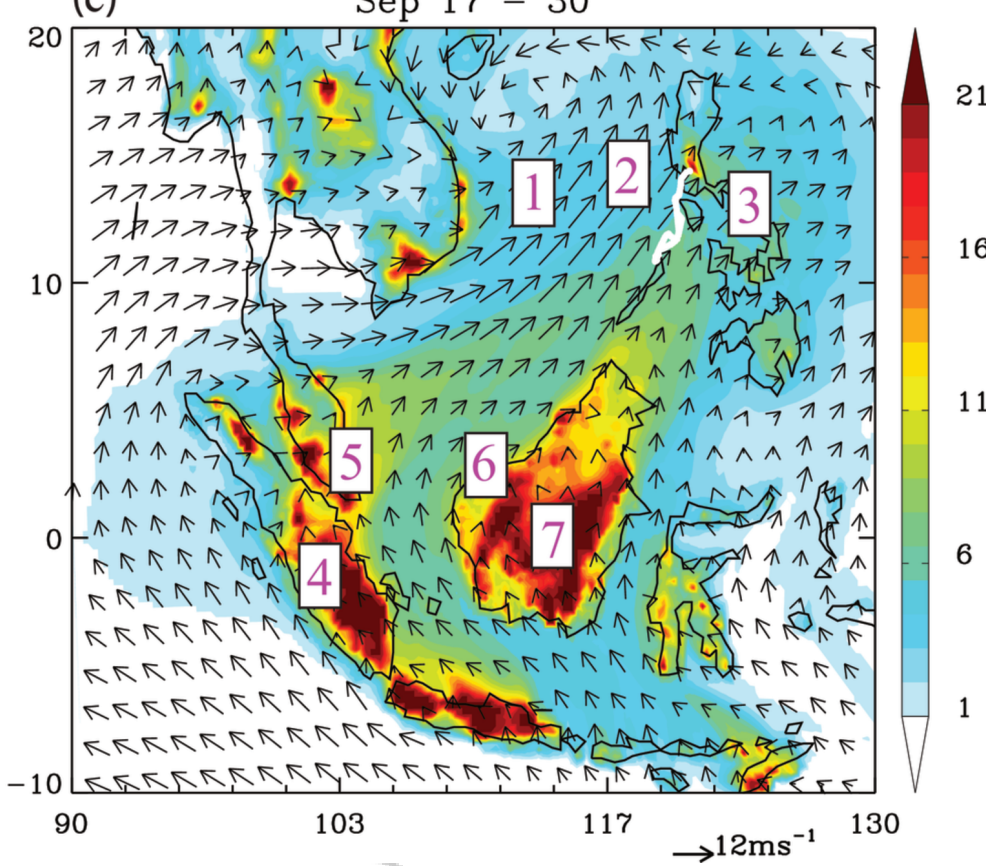

(b) Vasco

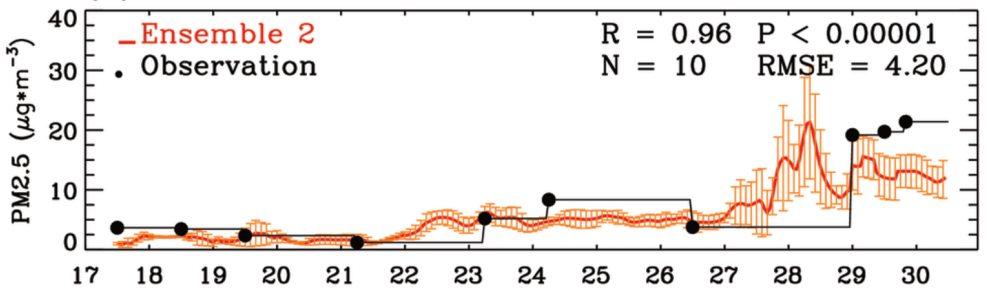

(d) Kuching

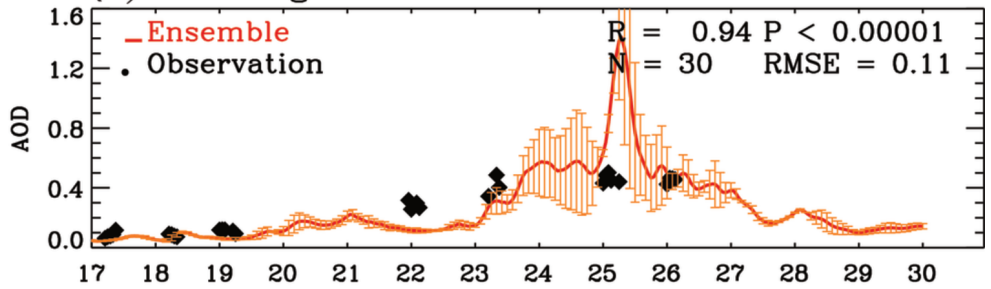

11

(e) Singapore

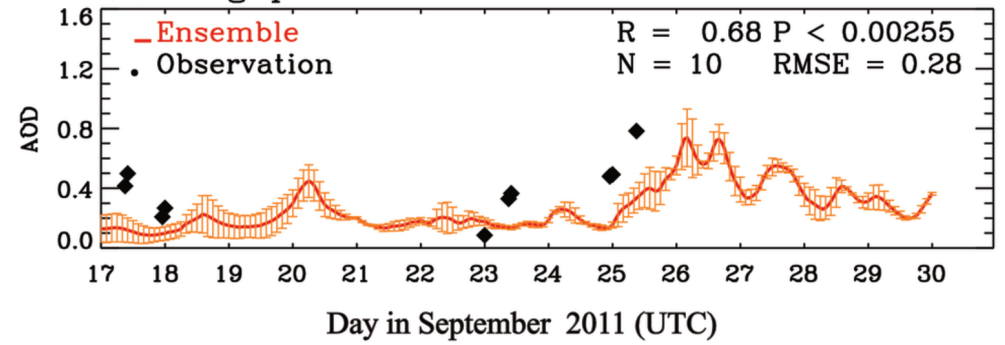

2016jd026241-f01-z-.eps 
(a) Vasco

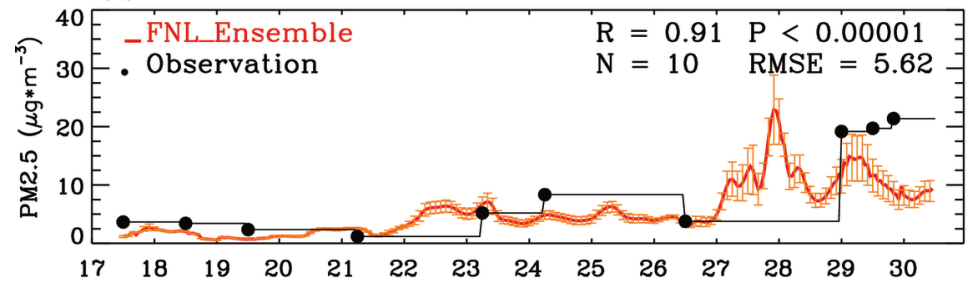

(b) Vasco

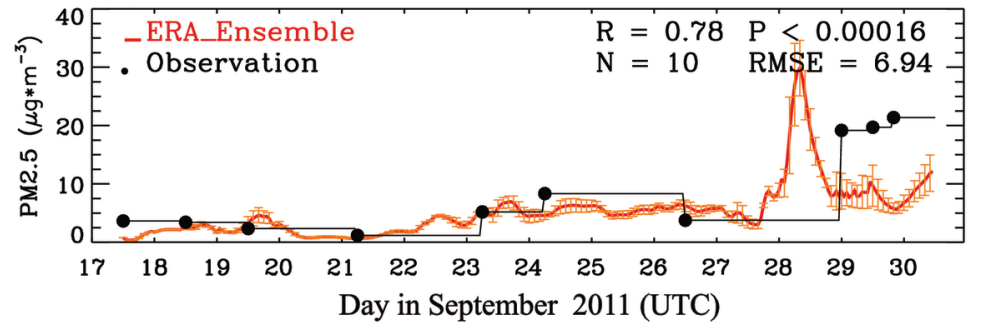

(c)

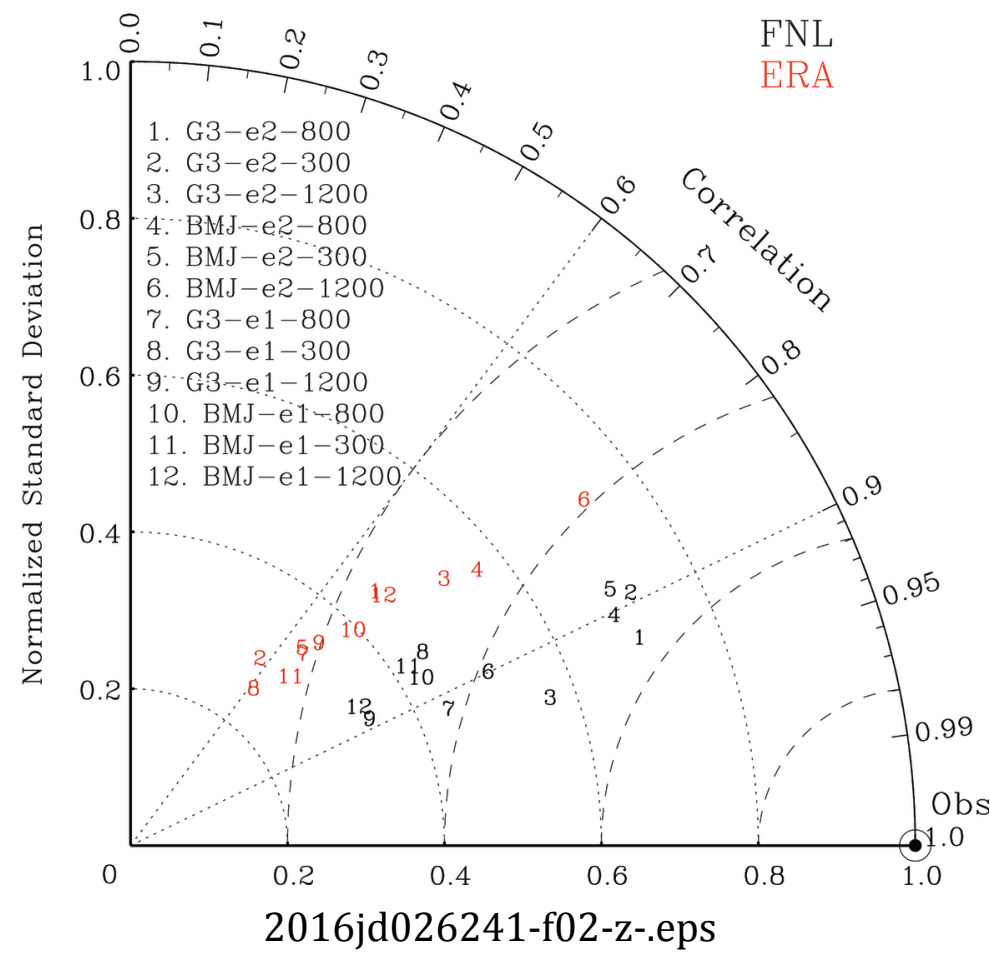

This article is protected by copyright. All rights reserved. 


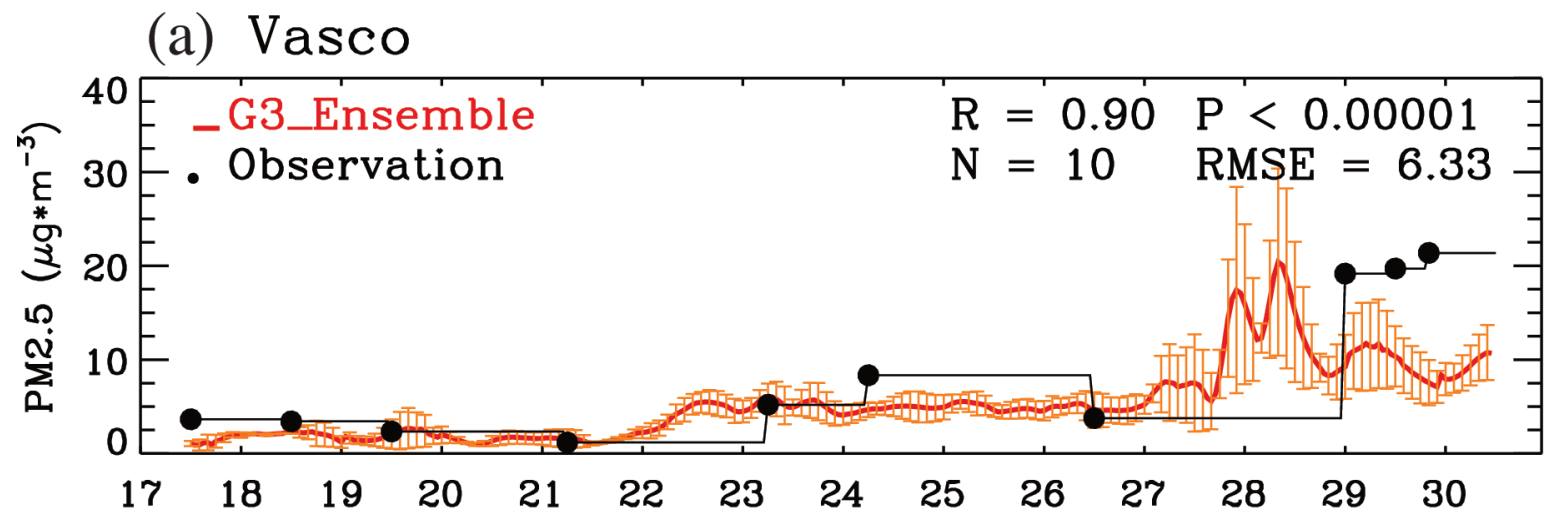

(b) Vasco

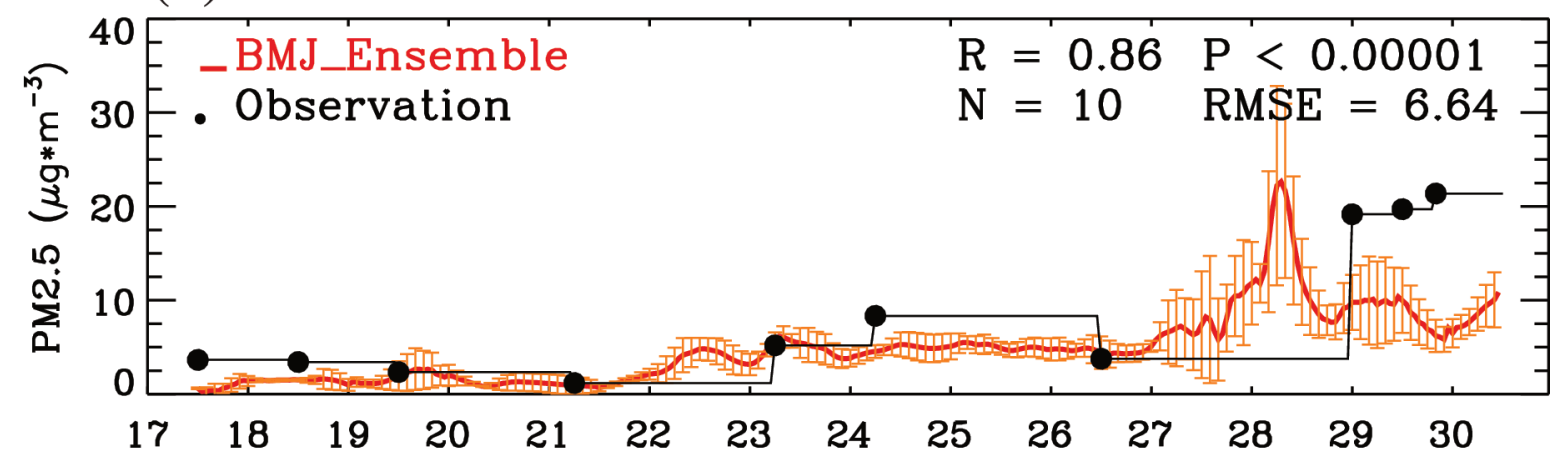

Day in September 2011 (UTC)

2016jd026241-f04-z-.eps 

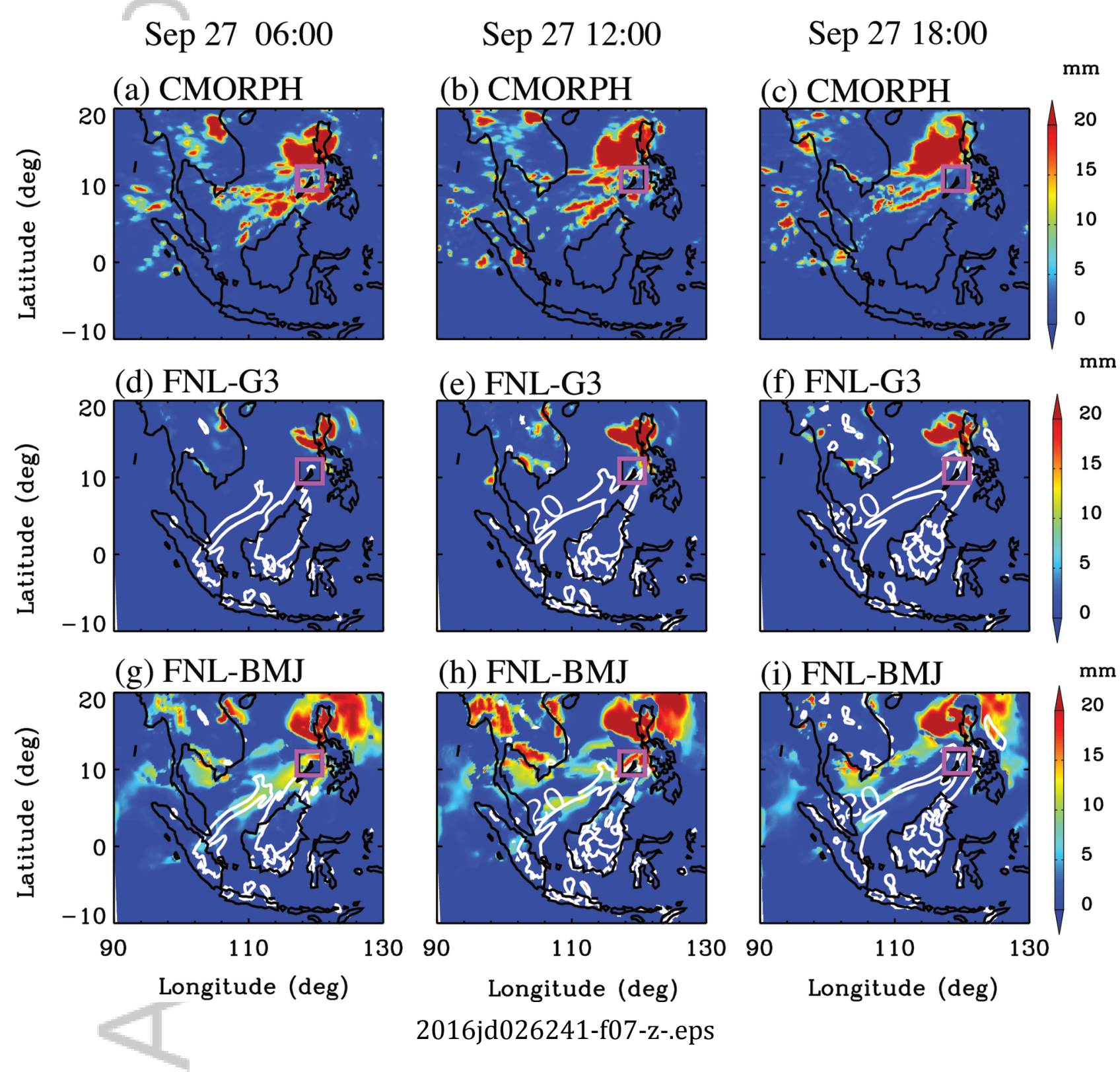

2016jd026241-f07-z-.eps

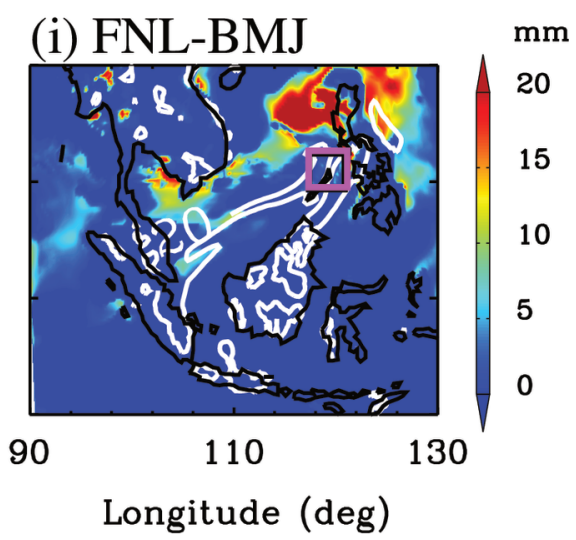

This article is protected by copyright. All rights reserved. 


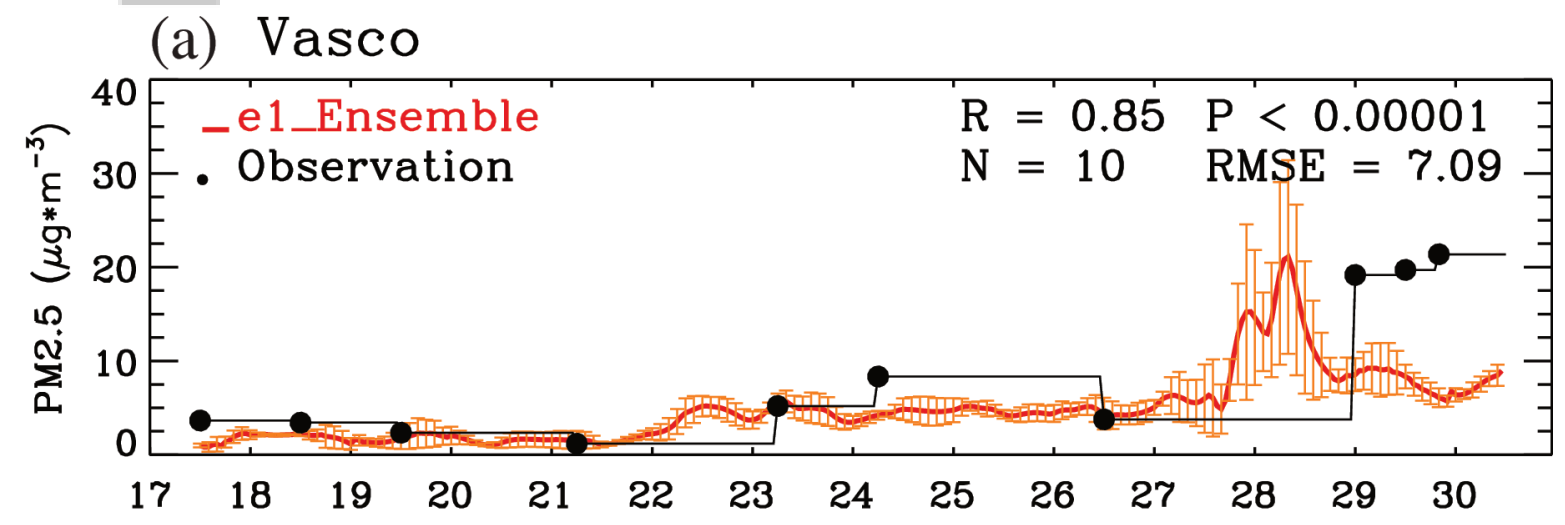

(b) Vasco

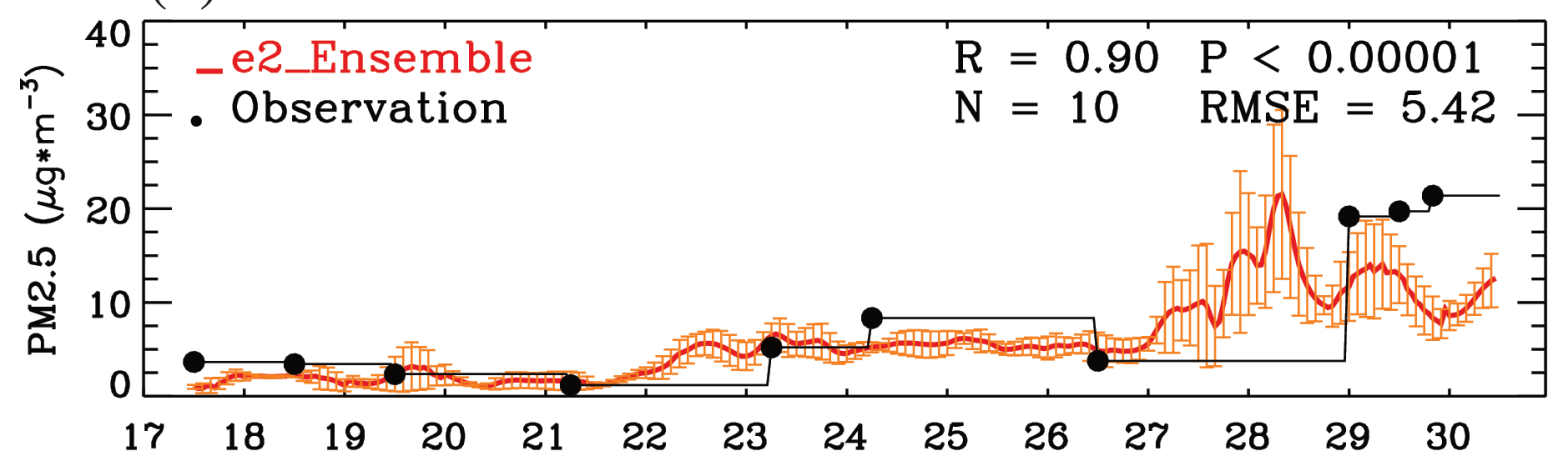

Day in September 2011 (UTC)

2016jd026241-f08-z-.eps 
(a) Terra

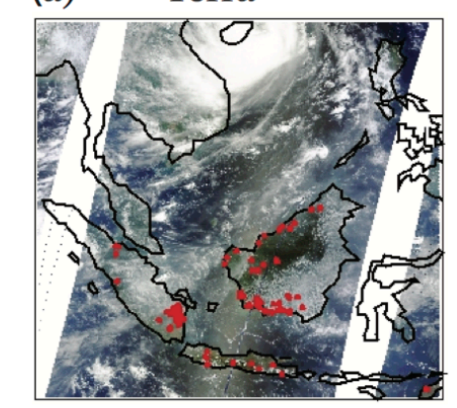

(e) Terra AOD

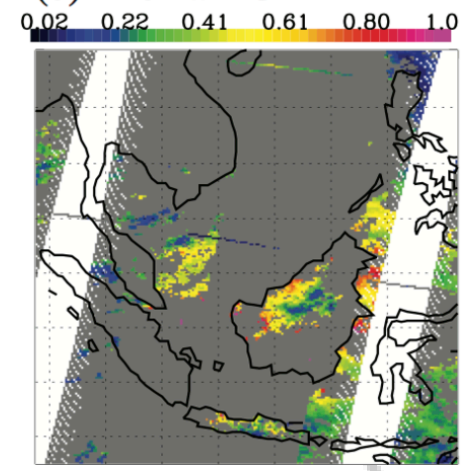

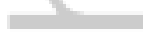
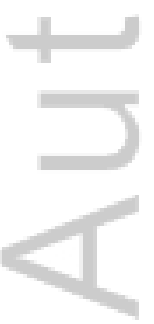

(b) Aqua

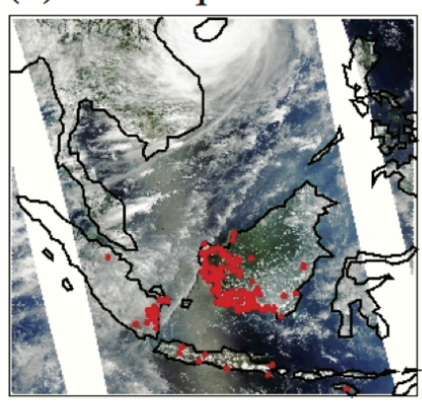

(f) Aqua AOD

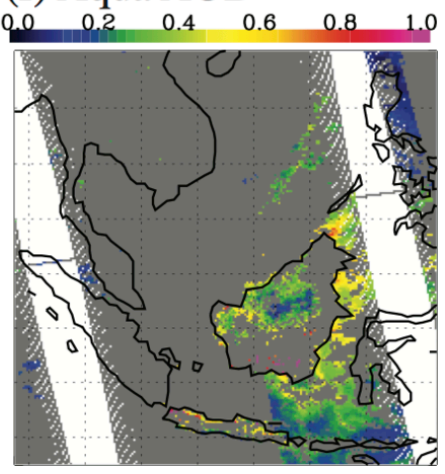

2016JD026241-f09-z-.png (c) FLAMBE

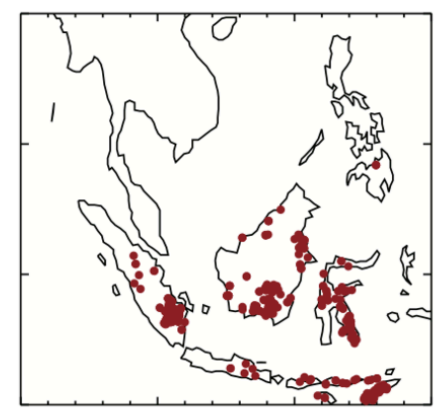

(g) Simulated AOD

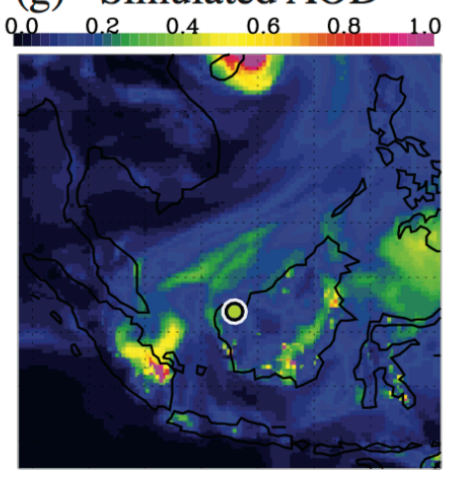

(h) Simulated AOD with update

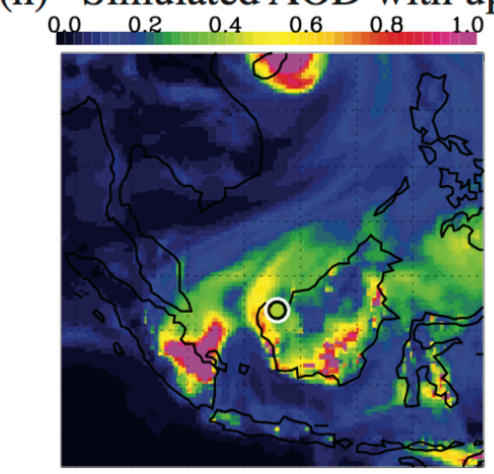

(d) Updated FLAMBE

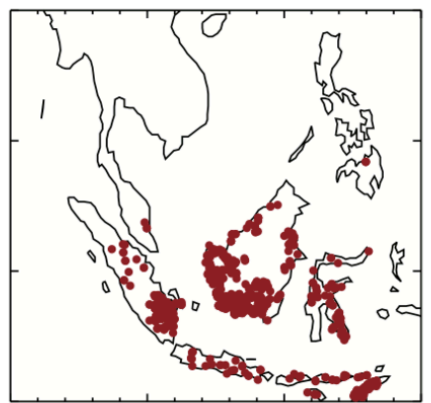

\section{(1)}



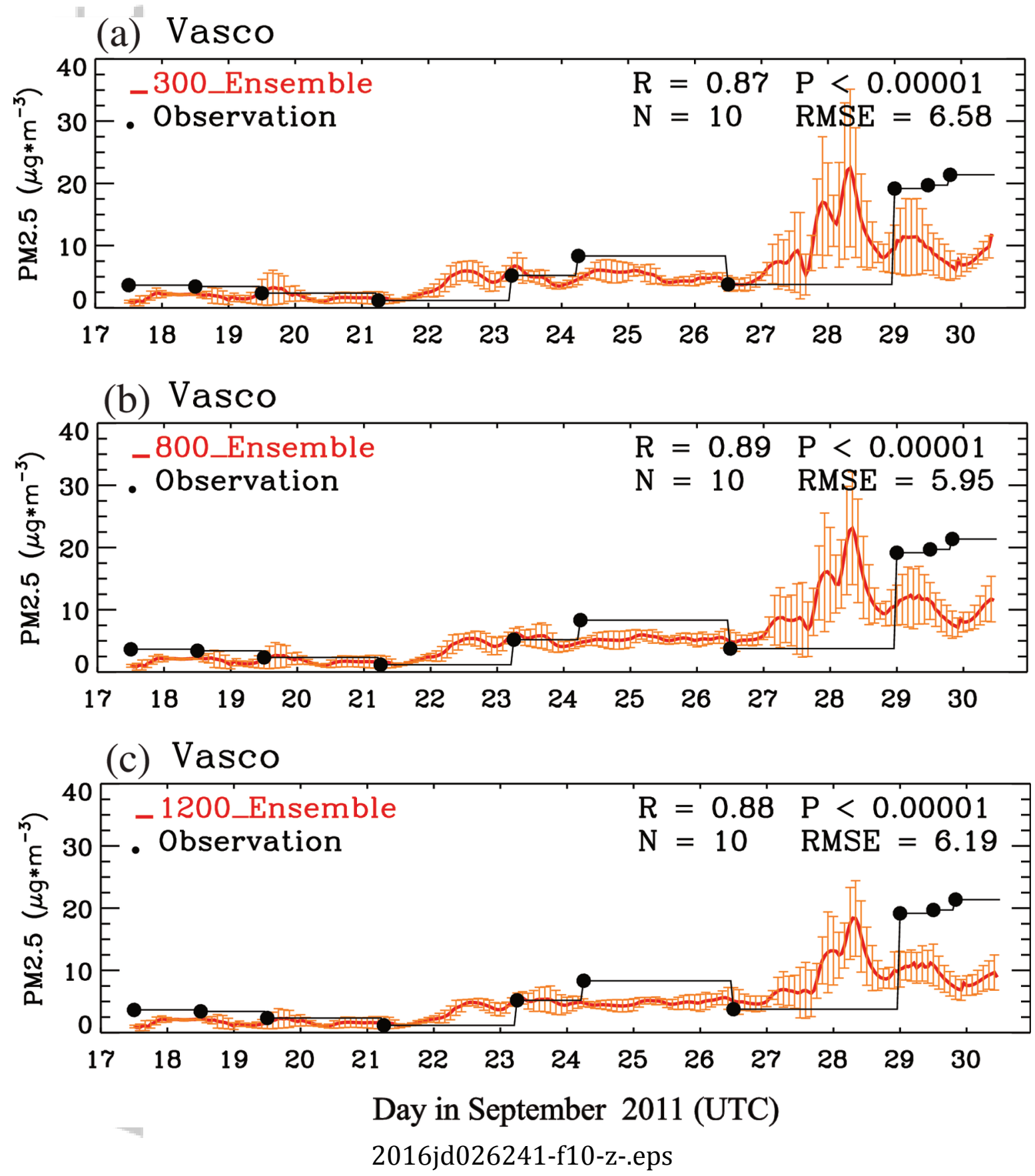

This article is protected by copyright. All rights reserved. 


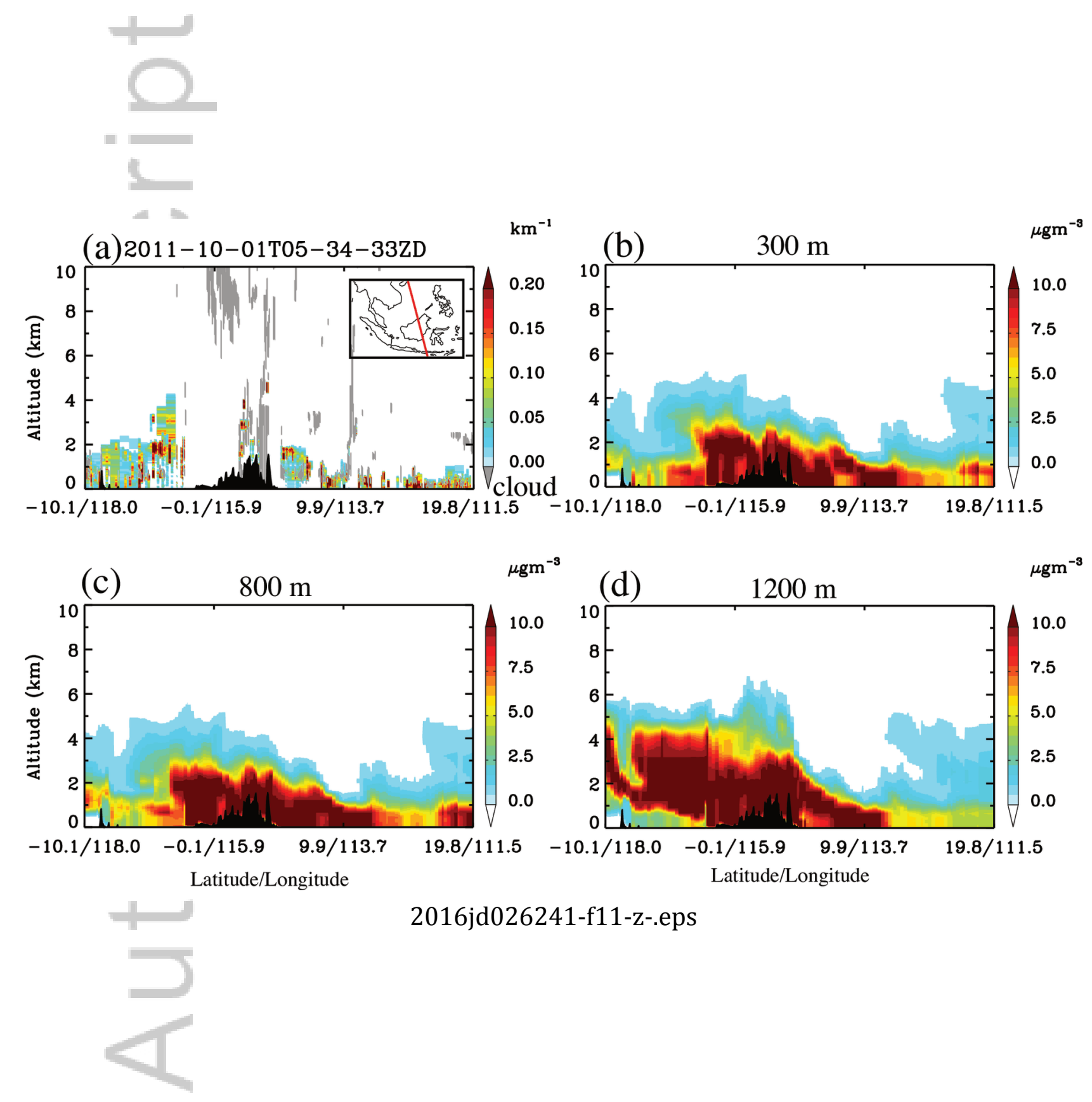

This article is protected by copyright. All rights reserved. 


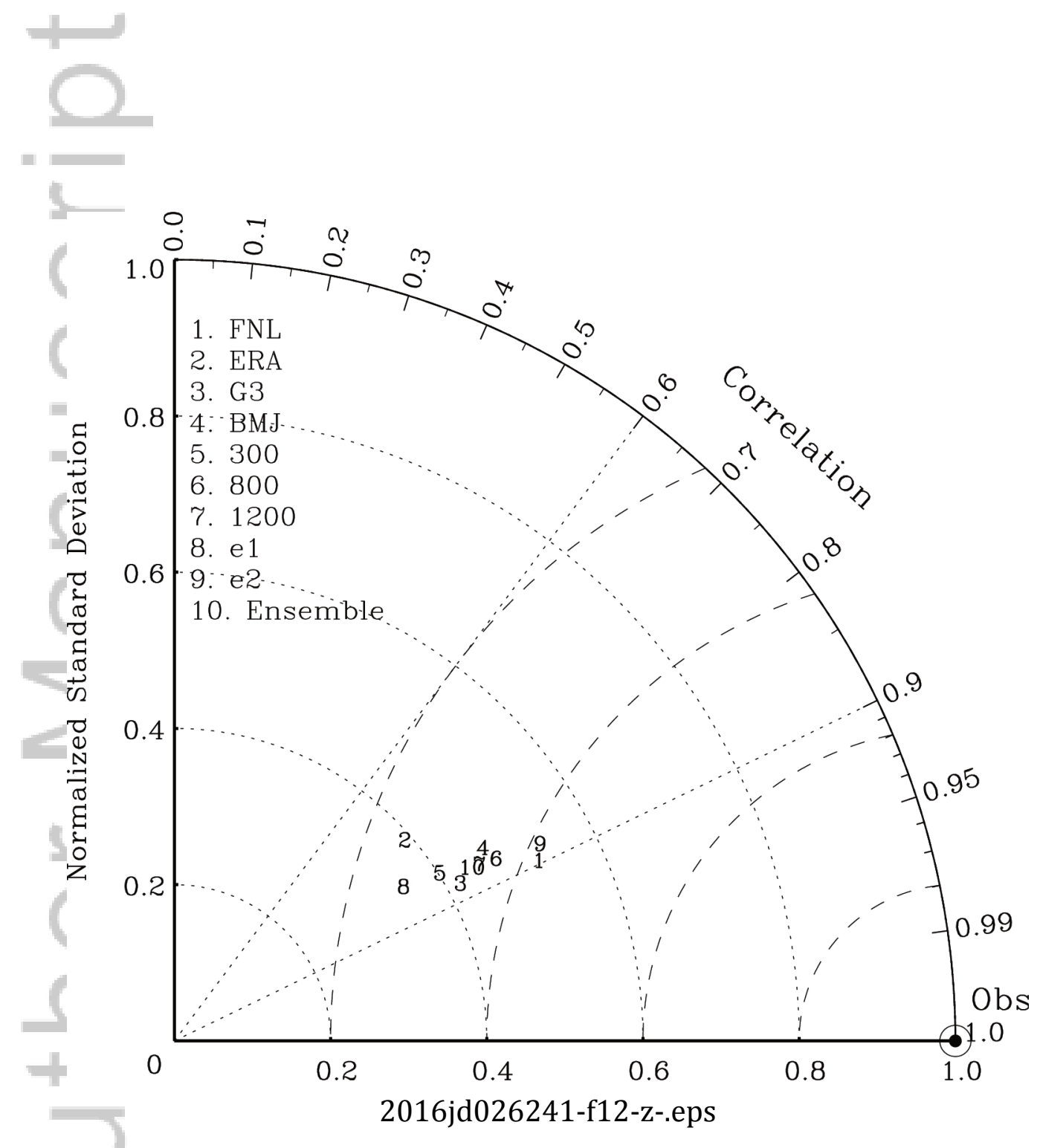

This article is protected by copyright. All rights reserved. 
